\title{
Intercomparison of Single-Column Numerical Models for the Prediction of Radiation Fog
}

\author{
Thierry Bergot, ${ }^{*}$ Enric Terradellas, ${ }^{+}$Joan Cuxart, ${ }^{\#}$ Antoni Mira, ${ }^{\text {O Olivier Liechti, }}{ }^{@}$ \\ Mathias Mueller, \& and Niels Woetmann Nielsen** \\ * Météo-France, Centre National de Recherches Météorologiques, Toulouse, France \\ + Instituto Nacional de Meteorología, Barcelona, Spain \\ \# Department de Fisica, Universitat de les Iles Balears, Madrid, Spain \\ @ Analysen und Konzepte, Winterthur, Switzerland \\ \& Institute of Meteorology, Climatology, and Remote Sensing, University of Basel, Basel, Switzerland \\ ** Danish Meteorological Institute, Copenhagen, Denmark
}

(Manuscript received 14 December 2005, in final form 17 August 2006)

\begin{abstract}
The short-term forecasting of fog is a difficult issue that can have a large societal impact. Radiation fog appears in the surface boundary layer, and its evolution is driven by the interactions between the surface and lower layers of the atmosphere. Current NWP models poorly forecast the life cycle of fog, and improved NWP models are needed before improving the prediction of fog. Six numerical model simulations are compared for two cases from the Paris-Charles de Gaulle (Paris-CdG) fog field experiment. This intercomparison includes both operational and research models, which have significantly different vertical resolutions and physical parameterizations. The main goal of this intercomparison is to identify the capabilities of the various models to forecast fog accurately. An attempt is made to identify the main reasons behind the differences among the various models. This intercomparison reveals that considerable differences among models exist in the surface boundary layer before the fog onset, particularly in cases with light winds. The lower-resolution models crudely forecast the nocturnal inversion, the strong inversion at the top of the fog layer, and the interactions between soil and atmosphere. This intercomparison further illustrates the importance of accurate parameterizations of dew deposition and gravitational settling on the prediction of fog.
\end{abstract}

\section{Introduction}

The prediction of visibility near the surface is a formidable challenge for the operational weather forecast services. Air traffic safety and operational efficiency depend heavily upon accurate and timely forecasts of reduced visibility conditions. Adverse visibility conditions can strongly reduce the efficiency of a terminal area's traffic flow. For example, at Paris-Charles de Gaulle international airport (Paris-CdG), the capacity of landing and takeoff is reduced by a factor of 2 in foggy conditions. The flow of air traffic into major airport terminals is reduced by poor visibility conditions, and fog is one of the major causes of aircraft delays.

Corresponding author address: T. Bergot, Météo-France, CNRM/GMME, 42, Avenue G. Coriolis, F-31057 Toulouse CEDEX, France.

E-mail: thierry.bergot@meteo.fr
Therefore, more reliable forecasts of fog are needed to allow air traffic managers to regulate traffic more effectively. Fog also has a significant impact on road and marine transportation. Improved numerical weather prediction (NWP) models are needed before improving the analysis and prediction of fog (e.g., Benjamin et al. 2004; Fowler et al. 2006). These improvements are necessary to meet the requirements of end users.

Various processes can reduce the visibility (e.g., radiation fog, advection fog, precipitation, or stratus lowering). This intercomparison work focuses on cases in which radiation fog conditions are encountered. Radiation fog is a consequence of the interaction between the surface and the lower layers of the atmosphere under stable atmospheric boundary layer conditions. These effects are still not well parameterized in current operational NWP models. Moreover, the horizontal and vertical resolutions of current NWP models (currently $5-10 \mathrm{~km}$ and three levels within the first $200 \mathrm{~m}$ of the

DOI: $10.1175 / J A M 2475.1$ 
atmospheric boundary layer) are larger than the corresponding characteristic fog scales $(100 \mathrm{~m}$ for the horizontal scale and a few meters for the vertical scale). As a consequence, current NWP models poorly forecast the life cycle of fog. Deficiencies in physical parameterizations and inaccurate initial conditions within the surface boundary layer can explain the poor quality of fog prediction. Although much is known about the structure of the convective boundary layer and the physical processes taking place within it, much less is known about the stable boundary layer (Terradellas et al. 2005). Several authors have demonstrated that the turbulence that develops in a stable boundary layer under conditions of both large static stability and large vertical wind shear is intermittent or sporadic, and the origin of this phenomenon is not understood well (Mahrt 1985, 1999; Horst and Doran 1986; Lenschow et al. 1988). Improved numerical model prediction of fog and low clouds can only be achieved by improving the parameterization of the complex physical mechanisms involved within the dry and moist surface boundary layer.

Radiation fog occurs predominantly during the winter season, typically within the stable boundary layers. The life cycle of a fog layer depends on the balance between cooling and moisture loss in the surface layer, so that surface exchanges and boundary layer processes play a fundamental role in the life cycle of a fog layer. Single-column (1D) models provide many insights into fog physics, despite the poor representation of horizontal heterogeneities. Several 1D models have been used to study fog layers (e.g., Musson-Genon 1987; Duynkerke 1991; Bergot and Guedalia 1994). Moreover, 1D models are currently used to forecast fog at the local scale (Clark 2002; Bergot et al. 2005; Terradellas and Cano 2006). In addition, they are helpful tools that can be used to understand better some small-scale processes in the boundary layer, especially the vertical turbulent exchanges. They are also useful for testing the performance of new parameterizations that may be later incorporated in 3D NWP models.

The main goal of this intercomparison is to identify the capabilities of various models to forecast fog accurately, and an attempt is made to identify the main reasons behind the differences among the various models. The effect of the vertical resolution on the prediction of fog will also be examined. Our intention is not to show that one NWP model is better than another. To focus on the relevant vertical processes influencing fog and the boundary layer, the numerical models used in this intercomparison are $1 \mathrm{D}$ models. The objective is to study boundary layer processes at the local scale using high-quality observations and numerical simulations.
By starting from the same initial conditions and by using the same mesoscale forcing, the differences among the model simulations arise from the disparate physical parameterizations and vertical resolutions.

Descriptions of the data used and of the participating models are briefly given in sections 2 and 3. The NWP forecasts are described and intercompared in section 4 for a radiation fog event and in section 5 for a near-fog event. Some conclusions of this intercomparison are drawn.

\section{Data collection}

Two cases corresponding to radiation fog conditions will be studied. These cases were taken from the observations collected during the fog field experiment carried out by Météo-France/Centre National de Recherches Météorologiques (CNRM) at Paris-CdG airport (Bergot et al. 2005). During this field experiment, the following measurements were taken: A 30-m meteorological tower collected observations of temperature and humidity in the surface boundary layer (levels of measurement: 1, 2, 5, 10, and $30 \mathrm{~m}$ ). Shortwave and longwave radiation fluxes were measured at the ground and on the roof of the airport terminal $(45 \mathrm{~m})$. Soil temperature and soil moisture were measured at four levels between the ground and $50 \mathrm{~cm}$ in depth $(-5,-10,-20$, and $-50 \mathrm{~cm})$. Horizontal visibility was measured at 12 locations over an area of $4 \mathrm{~km} \times 4 \mathrm{~km}$. Cloud ceiling was measured at four locations within an area of $4 \mathrm{~km} \times 4 \mathrm{~km}$. Added to this specific instrumentation dedicated to fog and low clouds, classical meteorological measurements were also available (pressure, precipitation, wind intensity, and direction).

All simulations performed by the participants were initialized using the same high-resolution atmospheric and soil profiles. These initial conditions were deduced from a local assimilation system using measurements from the field experiment (Bergot et al. 2005). The assimilation procedures used to construct the initial profiles are as follows: First, the atmospheric vertical profile of temperature and humidity is estimated in a 1D variational data assimilation framework. Second, if low clouds or fog are detected, adjustments of the atmospheric profiles are introduced to take into account the presence of clouds (under the hypothesis of a mixed cloud layer). Third, the vertical profiles of temperature and water content within the soil are estimated from observations. The data used by the participants of this intercomparison contain initial atmospheric profiles of temperature, water vapor mixing ratio, liquid water mixing ratio, wind up to $5500 \mathrm{~m}$, and initial soil profiles of temperature and moisture down to $2 \mathrm{~m}$ in depth. The 
TABLE 1. The 1D models involved in the intercomparison. The vertical resolution is summarized by the number of levels (nlev) in the lowest $50 \mathrm{~m}$ and in the lowest $200 \mathrm{~m}$.

\begin{tabular}{|c|c|c|c|c|c|c|}
\hline Model (institute) & Scientists & $\begin{array}{l}\text { Nlev } \\
<50 \mathrm{~m}\end{array}$ & $\begin{array}{c}\text { Nlev } \\
<200 \mathrm{~m}\end{array}$ & Turbulence & Microphysics & SVAT \\
\hline $\begin{array}{l}\text { HIRLAM-INM (INM, } \\
\text { Spain) }\end{array}$ & E. Terradellas & 1 & 3 & $\begin{array}{l}\text { CBR, Cuxart et al. } \\
\text { (2000) }\end{array}$ & $\begin{array}{l}\text { STRACO, } \\
\text { Sass (1997) }\end{array}$ & $\begin{array}{l}\text { ISBA, Noilhan and } \\
\text { Planton (1989) }\end{array}$ \\
\hline $\begin{array}{l}\text { tBM (Analysen und } \\
\text { Konzepte, } \\
\text { Switzerland) }\end{array}$ & O. Liechti & 2 & 7 & No & Bulk & Two layers \\
\hline $\begin{array}{l}\text { HIRLAM-DMI (DMI, } \\
\text { Denmark) }\end{array}$ & N. W. Nielsen & 13 & 20 & $\begin{array}{l}\text { CBR modified, } \\
\text { Cuxart et al. } \\
(2000)\end{array}$ & $\begin{array}{l}\text { STRACO, } \\
\text { Sass (1997) }\end{array}$ & $\begin{array}{l}\text { ISBA modified, } \\
\text { Noilhan and } \\
\text { Planton (1989) }\end{array}$ \\
\hline $\begin{array}{l}\text { COBEL-ISBA } \\
\text { (Météo-France, } \\
\text { France) }\end{array}$ & T. Bergot & 13 & 20 & $\begin{array}{l}\text { Estournel and } \\
\text { Guedalia (1987); } \\
\text { Bougeault and } \\
\text { Lacarrere (1989) }\end{array}$ & Bulk & $\begin{array}{l}\text { ISBA-DF, Boone } \\
\text { (2000) }\end{array}$ \\
\hline $\begin{array}{l}\text { COBEL-Noah } \\
\text { (University of Basel, } \\
\text { Switzerland) }\end{array}$ & M. Mueller & 18 & 30 & $\begin{array}{l}\text { Mueller et al. } \\
\text { (2005) }\end{array}$ & Bulk & $\begin{array}{l}\text { Noah, Ek et al. } \\
\text { (2003) }\end{array}$ \\
\hline $\begin{array}{l}\text { Méso-NH (Universitat } \\
\text { de les Iles Balears, } \\
\text { Spain) }\end{array}$ & $\begin{array}{l}\text { J. Cuxart, } \\
\text { A. Mira }\end{array}$ & 50 & 89 & $\begin{array}{l}\text { CBR, Cuxart et al. } \\
(2000)\end{array}$ & Bulk & $\begin{array}{l}\text { ISBA, Noilhan and } \\
\text { Planton (1989) }\end{array}$ \\
\hline
\end{tabular}

soil and vegetation properties deduced from local measurements are prescribed. The mesoscale forcing is reduced to the geostrophic wind profile computed from the operational Aire Limitée Adaptation Dynamique Développement International (ALADIN) NWP model.

\section{Description of the 1D models}

Six different models participated in this intercomparison (see Table 1). The participants include national weather services, universities, and private institutions. Some of the models are operational [High-Resolution Limited-Area Model-Instituto Nacional de Meteorología (HIRLAM-INM), HIRLAM-Danish Meteorological Institute (HIRLAM-DMI), and Couche Brouillard Eau Liquide-Interactions between Soil, Biosphere, and Atmosphere (COBEL-ISBA)], and others are research models ["tBM," COBEL-Noah ("Noah" is an acronym denoting National Centers for Environmental Prediction-Oregon State UniversityU.S. Air Force-National Weather Service Office of Hydrologic Development), and Nonhydrostatic Mesoscale Model (Méso-NH)]. The vertical resolutions of the models are very different: a very fine mesh is used for Méso-NH and a crude vertical resolution is used for HIRLAM-INM. The models also differ in their treatment of turbulence, radiation, microphysics, and the soil-vegetation-atmosphere transfer (SVAT) scheme (see Table 1). A brief description of the models follows.

\section{a. HIRLAM-INM}

The HIRLAM-INM 1D model is a one-dimensional version of the operational HIRLAM-INM model used at INM (Spain). For this intercomparison, it used a vertical grid with 60 levels. The lowest level is approximately $30 \mathrm{~m}$ above the ground level. The physical parameterizations are the same as in its 3D counterpart, which is operationally run at INM for short-range forecasts: the Savijari-Sass scheme is used for radiation (Sass et al. 1994, 1-43), a Cuxart-Bougeault-Redelsberger (CBR) scheme is used for vertical diffusion in the boundary layer (Cuxart et al. 2000), and the Soft Transition Condensation (STRACO) scheme is used for moist processes (Sass 1997). The soil is represented by the ISBA scheme (Noilhan and Planton 1989), which models the exchange of heat, mass, and momentum between the surface and the overlying atmosphere.

\section{b. $t B M$}

The tBM model is a descendant of the two-dimensional (2D) model "REGTHERM" (Liechti 2002) and the 1D model "ALPTHERM" (Liechti and Neininger 1994) for convection in complex topography. tBM respects the area-elevation distribution of topography within the vertical column. The vertical resolution of tBM is $33 \mathrm{~m}$.

The physical package consists of parameterizations for longwave and shortwave radiative transfer, convective mixing, condensation/evaporation, and sedimentation of liquid water. Turbulent mixing is not yet param- 
eterized in tBM. Two soil temperatures are used: the skin temperature and the preset annual variation of soil temperature. Their difference is proportional to the soil heat flux. Soil moisture is only treated at the surface. To participate in this model intercomparison, tBM was used in the $1 \mathrm{D}$ version with flat topography.

\section{c. HIRLAM-DMI}

This is a $1 \mathrm{D}$ version of the operational DMIHIRLAM model. The latter model system is based on HIRLAM reference version 6.2.3. It uses a revised version of the CBR scheme (Cuxart et al. 2000) for turbulent exchanges in which the turbulent mixing length has been modified. The land surface scheme is based on ISBA (Noilhan and Planton 1989) with a modified roughness for bare soil and low vegetation. For this intercomparison, the number of model levels was increased from 40 to 80 , with the lowest level at $50 \mathrm{~cm}$ above the ground. No adjustment to the increased vertical resolution was made in the physical parameterizations, except in the STRACO scheme (Sass 1997) for moist processes, where an automatic adjustment to changes in model resolution is a part of the parameterization. More information about HIRLAMDMI was available online at the time of writing (http:// www.dmi.dk).

\section{d. COBEL-ISBA}

The atmospheric high-resolution 1D model COBELISBA has been developed in collaboration between the Laboratoire d'Aérologie (Université Paul Sabatier/ CNRS, Toulouse, France) and Météo-France. A detailed description can be found in Bergot and Guedalia (1994). The COBEL model equations are solved on a high-resolution vertical grid: near the surface, in the region of significance for fog and low clouds (i.e., below $200 \mathrm{~m}$ ), numerical computations are made on 20 vertical levels (the first level is at $50 \mathrm{~cm}$ ). The physical package used in COBEL-ISBA includes a parameterization of boundary layer turbulent mixing for stable (Estournel and Guedalia 1987), neutral, and unstable conditions (Bougeault and Lacarrere 1989); a microphysical parameterization adapted to fog and low clouds; and detailed longwave and shortwave radiation transfer schemes.

The COBEL model is coupled with the seven-layer SVAT scheme ISBA-DF (where DF stands for diffusion; Boone 2000; Boone et al. 1999).

\section{e. COBEL-Noah}

The atmospheric model is a modified version of the high-resolution COBEL model described in Bergot and
Guedalia (1994). The main modifications concern the turbulence scheme and the parameterization of the interaction between the soil and the atmosphere (Mueller et al. 2005). The vertical resolution is defined by 30 levels in the lowest $200 \mathrm{~m}$. The surface scheme is the Noah land surface model (Chen et al. 1997; Ek et al. 2003). Prognostic equations for soil heat and moisture are solved on a 10-layer grid, where the first soil layer has a thickness of $0.25 \mathrm{~cm}$.

\section{f. Méso-NH}

Méso-NH (Lafore et al. 1998) is the French research community nonhydrostatic mesoscale model (http:// www.aero.obs-mip.fr). It has been jointly developed by the Laboratoire d'Aérologie and by Météo-France/ CNRM. The model is intended to be applicable to all scales ranging from large (synoptic) scales to small (large eddy) scales.

In this intercomparison, the model is used in its single-column version, which uses the same physics package as the complete 3D model. Here the chosen options are the CBR scheme for the turbulent diffusion (Cuxart et al. 2000), the two-layer ISBA model for the soil-vegetation processes (Noilhan and Planton 1989), and the radiation scheme by Morcrette (1991). The model is run using a resolution of $1 \mathrm{~m}$ near the ground.

\section{Radiation fog event}

\section{a. Description of the event}

The first case studied, called "FOG," corresponds to a classical radiation fog that took place during the night between 1 and 2 October 2003 at Paris-CdG. This night was characterized by a weak wind of $1-2 \mathrm{~m} \mathrm{~s}^{-1}$ (Fig. 1a). The nocturnal cooling near the ground was strong at the beginning of the night, corresponding to about $3.5 \mathrm{~K}$ between 1700 and 2000 UTC (Fig. 1b). These conditions led to the creation of a nocturnal inversion before the formation of a fog layer, with a temperature difference of about $1.5 \mathrm{~K}$ between 1 and $30 \mathrm{~m}$ at 2000 UTC. The fog appeared at the ground near 2030 UTC and rapidly became dense (Fig. 2). As the fog grew, a low-level mixed layer corresponding to the fog layer (called mixed fog layer) appeared near the surface. The vertical extension of this mixed fog layer became significant (more than $45 \mathrm{~m}$ ) after the middle of the night. This period in the evolution of the fog layer was characterized by the disappearance of the radiative cooling inside the fog layer, leading to a nearly constant temperature within the fog layer. After sunrise, the fog layer dissipated rapidly and the visibility at the ground became greater than $1000 \mathrm{~m}$ near 0630 UTC. Rapid 

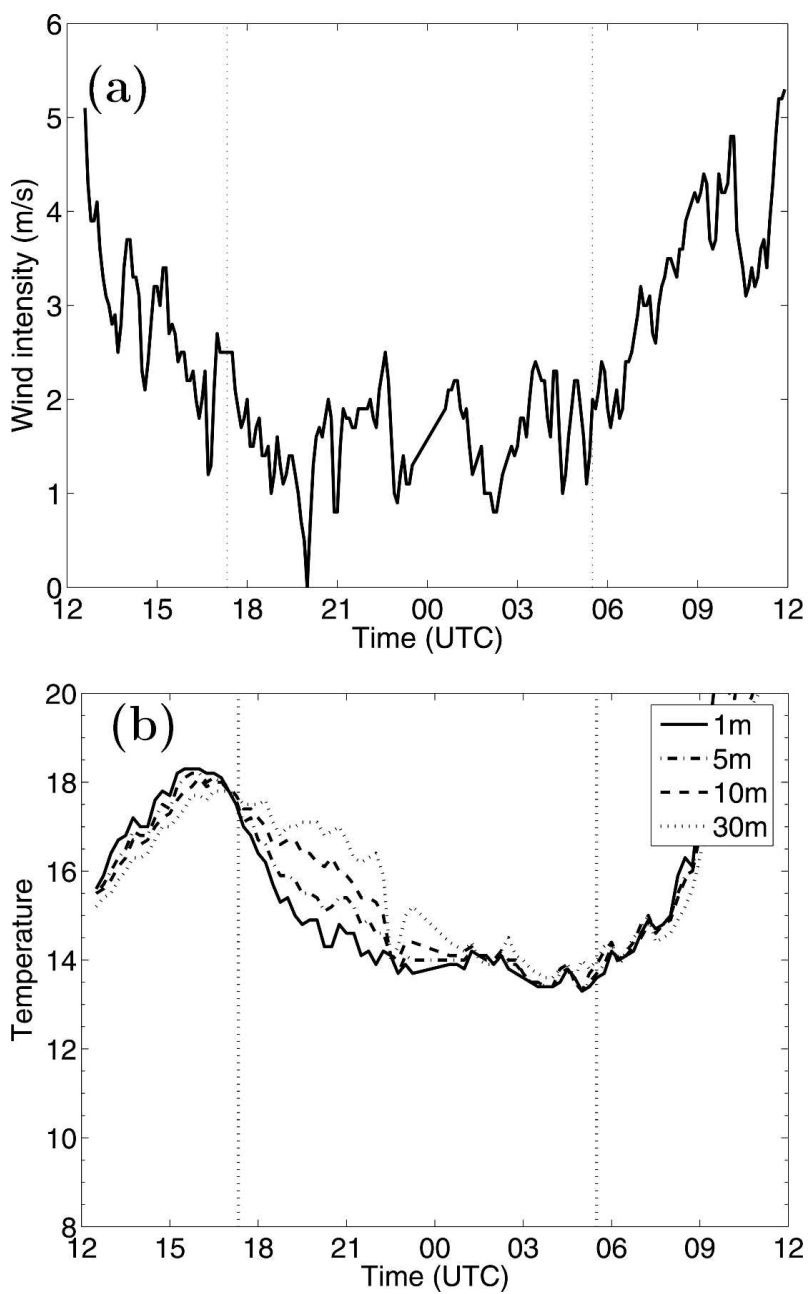

FIG. 1. Temporal evolution of the (a) wind intensity measured at $10 \mathrm{~m}$ and (b) temperature measured at $1,5,10$, and $45 \mathrm{~m}$ for the FOG case. The dotted line corresponds to the sunset and sunrise.

variations of the visibility were observed during the dissipation phase.

To compare the models at different stages during the life cycle of this fog event, four sets of initial conditions have been compiled. The models have been initialized at four different times during the night: 1800 UTC (the onset phase of the fog layer), 2100 UTC (the deepening, phase of the development phase of the fog layer), 0000 UTC (the mature phase of the development phase of the fog layer), and 0300 UTC (the dissipation phase of the fog layer).

\section{b. The onset phase}

The simulations presented hereinafter have been initialized at the beginning of the night (1800 UTC) before the fog onset. The forecast fog occurrence is plotted in Fig. 3a. All of the models forecast a fog event during

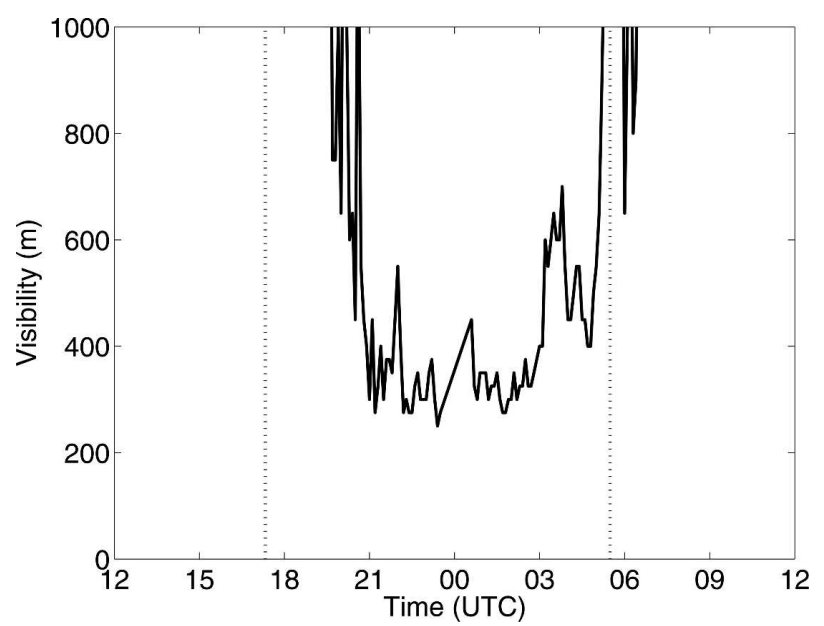

FIG. 2. Temporal evolution of the horizontal visibility measured at $2 \mathrm{~m}$ for the FOG case. The dotted line corresponds to the sunset and sunrise.

the night. However, the onset time varies from 2000 (HIRLAM-DMI) to 0100 UTC (HIRLAM-INM). The low-resolution models do not accurately forecast the fog onset at the beginning of the night. Even for this classical radiation fog event and relatively short term prediction (initialization at 1800 UTC and observed fog from 2030 UTC), the dispersion of the forecast fog onset is $5 \mathrm{~h}$. The time-height cross section of the cloud water is plotted in Fig. 4. The difference among the models is very large with respect to the vertical development of the condensed layer: it varies from $10 \mathrm{~m}$ for HIRLAM-DMI to $130 \mathrm{~m}$ for tBM at 0000 UTC. The fog layer simulated by tBM appears at the beginning of the night and evolves rapidly into a low cloud with a base at about $40 \mathrm{~m}$. Moreover, the liquid water content inside the fog layer is very different among the models, with values varying from 0.03 (HIRLAM-DMI) to $0.9 \mathrm{~g}$ $\mathrm{kg}^{-1}$ (Meso-NH). Meso-NH, which does not have a sedimentation term in its microphysical parameterization, generates an unrealistic liquid water content at the top of the fog layer. This point will be studied in the next section.

Figure 5 shows the profiles of temperature and specific humidity at 1900 UTC (+1-h forecast). The 1D models produce very different atmospheric cooling rates near the ground, whereas above $100 \mathrm{~m}$ the simulations are very similar. For example, the 2-m temperature varies from $287 \mathrm{~K}$ for COBEL-Noah (a cooling rate of $3 \mathrm{~K} \mathrm{~h}^{-1}$ ) to $289.7 \mathrm{~K}$ for HIRLAM-DMI (a cooling rate of $0.3 \mathrm{~K} \mathrm{~h}^{-1}$ ). At the beginning of the night, COBEL-Noah forecasts a significant cooling at the ground (a temperature about $2 \mathrm{~K}$ colder than observed) and a significant dew deposition (a water vapor mixing ratio about $1 \mathrm{~g} \mathrm{~kg}^{-1}$ less than the observation). 

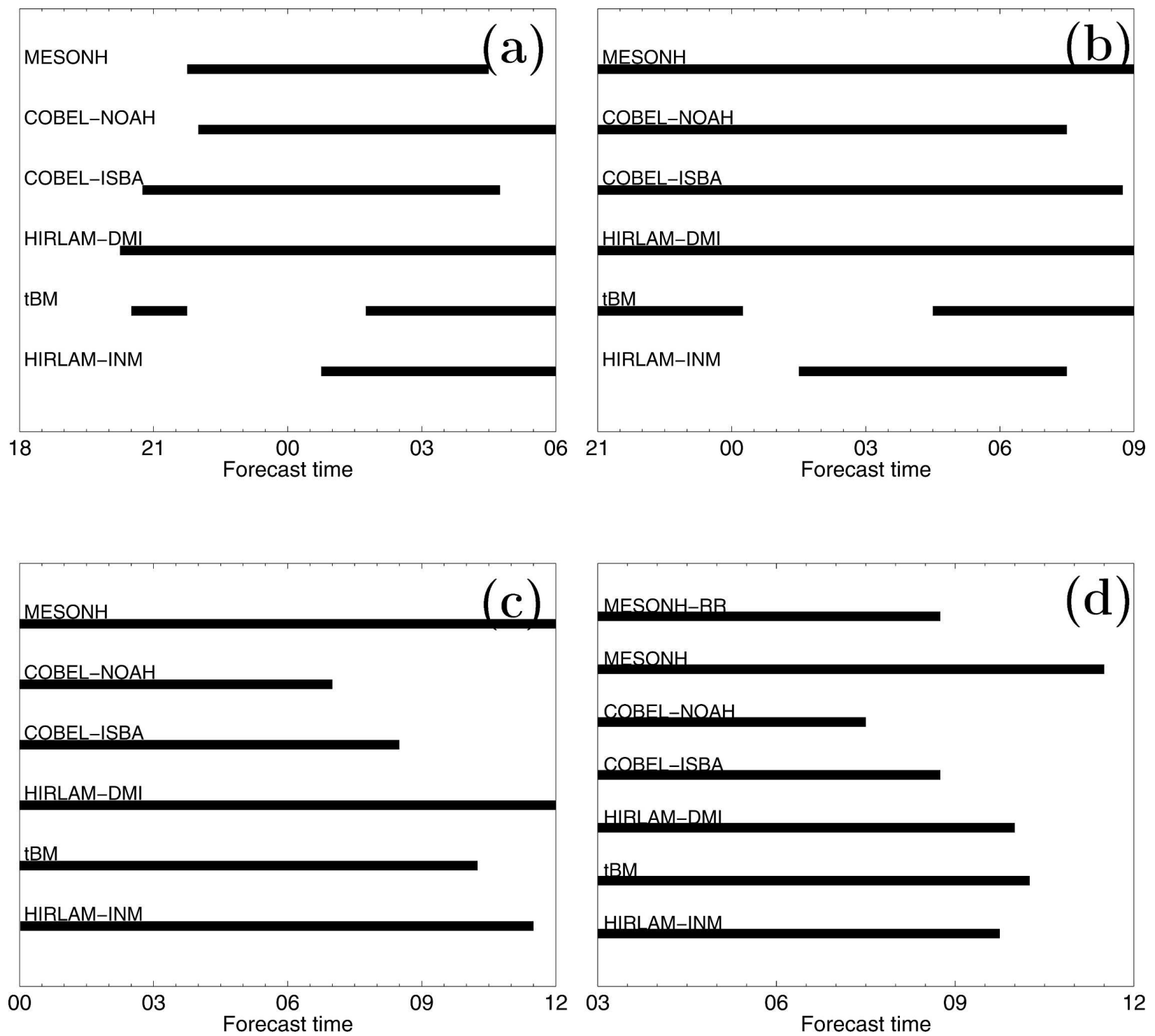

FIG. 3. The forecast occurrence of fog for simulations initialized at (a) 1800, (b) 2100, (c) 0000, and (d) 0300 UTC for the FOG case. The black lines correspond to forecast occurrence of fog. Méso-NH-RR simulation is only done at 0300 UTC. Observed fog formation: 2030 UTC; observed fog burn-off: 0730 UTC.

This decoupling between the atmosphere and the surface has not been observed and is only simulated by COBEL-Noah. The coarser-resolution models (HIRLAM-INM and tBM) have a realistic cooling near the ground. However, the nocturnal inversion and, in particular, the depth of the inversion are crudely forecast. To display the differences among the simulations, the average and dispersion for both temperature and water vapor at 2 and $45 \mathrm{~m}$ are plotted in Fig. 6 . At the beginning of the night, the mean of the various simulations leads to a nocturnal cooling close to the observed value of about $1 \mathrm{~K} \mathrm{~h}^{-1}$ at $2 \mathrm{~m}$. However, a strong dispersion among the simulations is observed: between
0.3 (HIRLAM-DMI) and $3 \mathrm{~K} \mathrm{~h}^{-1}$ (COBEL-Noah). For the +3 -h forecast (i.e., at the time of fog formation), the dispersion between the models for the 2-m parameters is about $3.5 \mathrm{~K}$ for temperature and $2 \mathrm{~g} \mathrm{~kg}^{-1}$ for water vapor. At $45 \mathrm{~m}$, all of the models agree with the observed values in terms of both temperature and humidity. This result illustrates the significant dispersion among the models near the ground before the formation of the fog layer, even for very short term forecasts.

The profile of net longwave radiation computed from the different models at 1800 UTC is plotted in Fig. 7. Note that the models have the same atmospheric profiles at this time (initial conditions) and that differences 
HIRLAM-INM

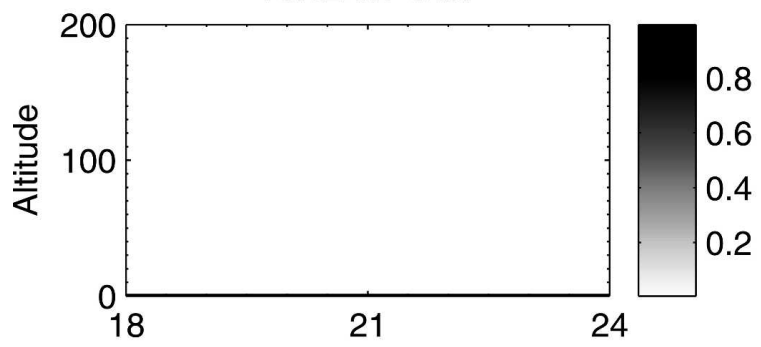

HIRLAM-DMI
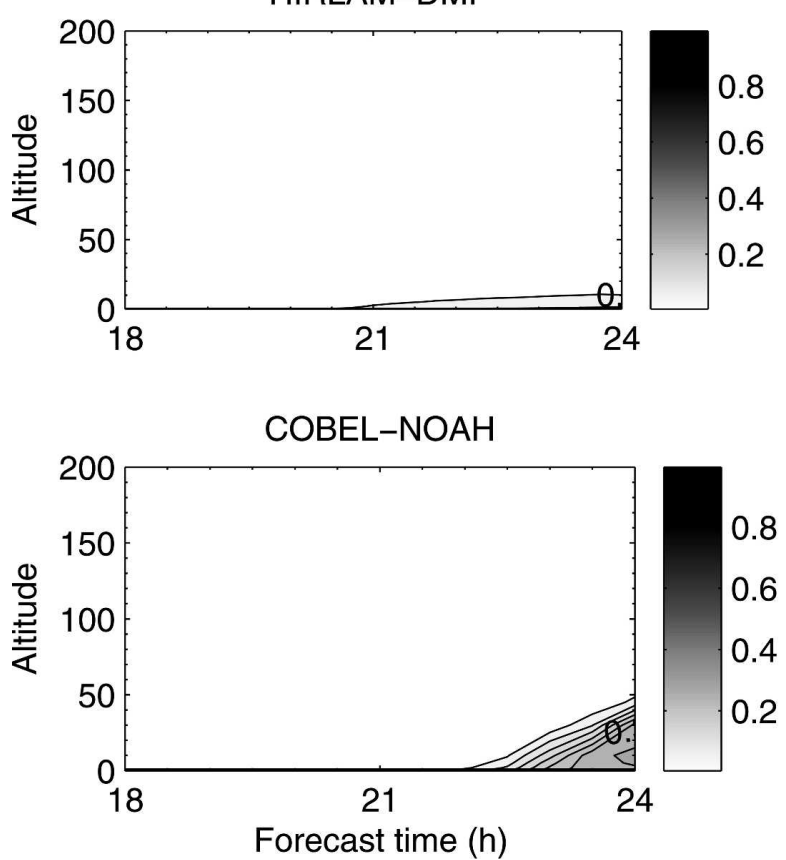

tBM

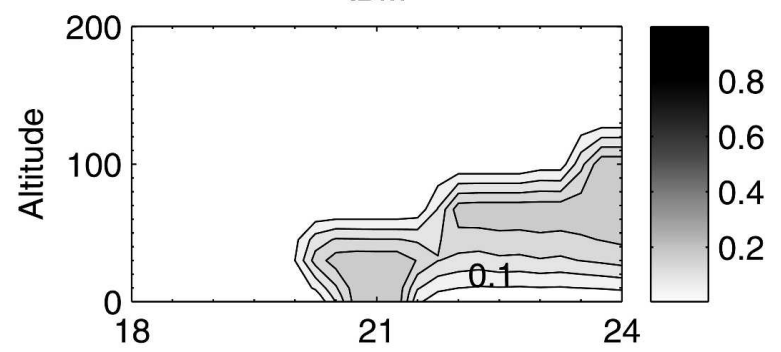

COBEL-ISBA
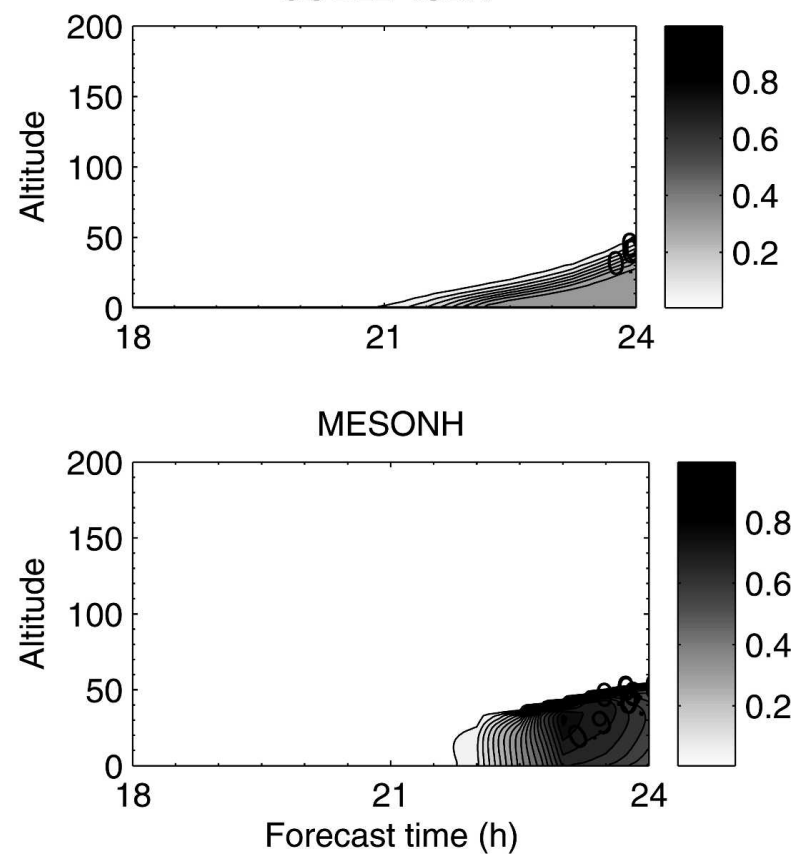

FIG. 4. Time-height cross section of the cloud water content forecast by the various models initialized at 1800 UTC for the FOG case (isoline every $0.05 \mathrm{~g} \mathrm{~kg}^{-1}$ ).

are only a consequence of the different radiative parameterizations. The dispersion among the net radiative fluxes is on the order of $30 \mathrm{~W} \mathrm{~m}^{-2}$ and shows no significant variation with altitude. However, models produce very different radiative profiles, with a divergence between the ground and a 500-m height ranging from 7 (tBM) to $26 \mathrm{~W} \mathrm{~m}^{-2}$ (Méso- $\mathrm{NH}$ ).

\section{c. The development phase}

The simulations presented hereinafter have been initialized at 2100 UTC to study the growing phase of the fog layer and at 0000 UTC to study the mature phase of the fog layer.

First, in terms of the simulations initialized at 2100 UTC, the evolution of the fog layer is very different among the models. There are considerable differences in the height of the fog layer and the liquid water content. Méso-NH, which does not include a gravitational settling term in the microphysical parameterization, has an unrealistic cloud water content inside the fog layer (more than $1 \mathrm{~g} \mathrm{~kg}^{-1}$ ). As for the simulations initialized at 1800 UTC, the fog layer simulated by tBM evolves rapidly into a stratiform cloud, reaching the ground at the end of the night. HIRLAM-DMI shows large oscillations in cloud water content at the top of the fog layer, which might be due to an exceedingly long time step (this point needs to be studied in future work). The lower-resolution model, HIRLAM-INM, cannot realistically simulate the first few hours of the growing phase, when the fog layer top is lower than the first vertical level (about $30 \mathrm{~m}$ ). Figure 8 shows the profiles of temperature and specific humidity at 0000 UTC for the +3 -h forecasts. The models produce greatly different atmospheric profiles. Three models (COBELISBA, COBEL-Noah, and Méso-NH) develop a mixed fog layer, with various depths. This kind of vertical 

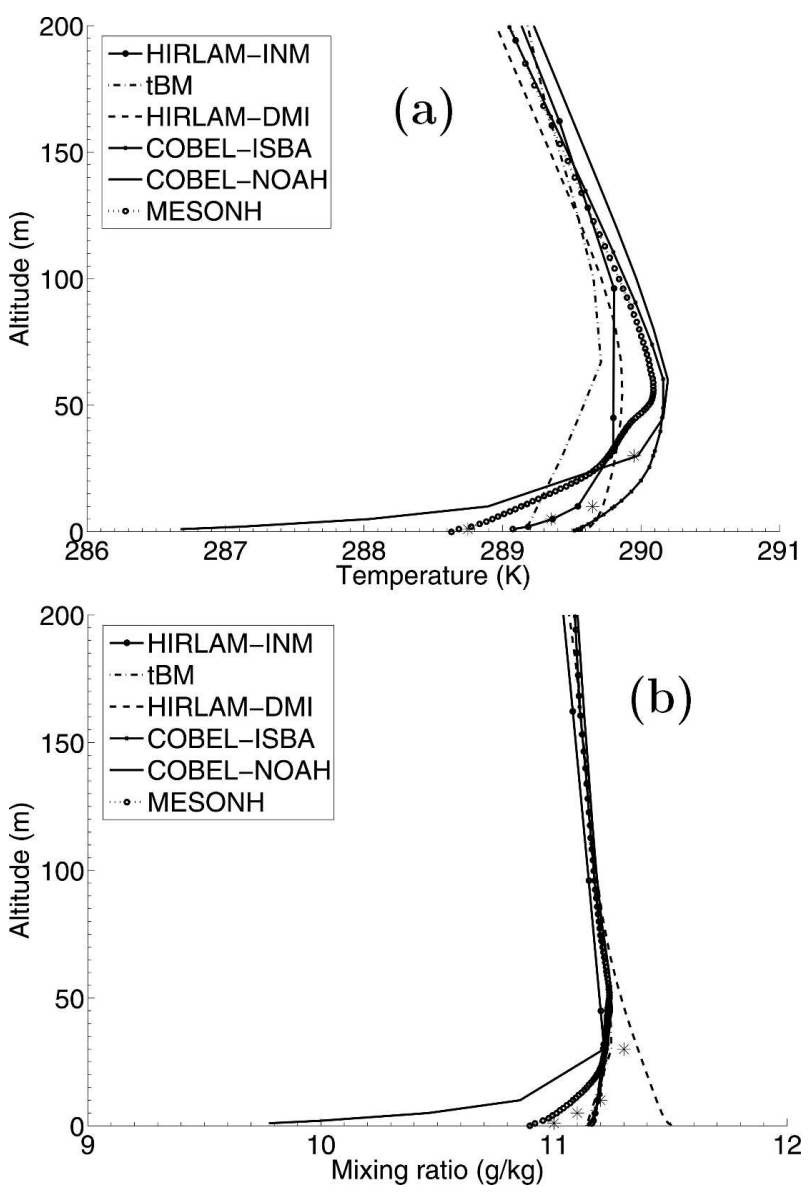

FIG. 5. (a) Temperature and (b) water vapor mixing ratio profiles at 1900 UTC (+1-h forecast) for simulations initialized at 1800 UTC for the FOG case. The observations are plotted with asterisks.

structure is typical for radiation fog and is confirmed with the observations for this studied case. However, the simulated fog layer is colder than the observed one. The tBM is the warmest and most moist model within the surface layer (about $288 \mathrm{~K}$ and $11 \mathrm{~g} \mathrm{~kg}^{-1}$ ), and COBEL-Noah is the coldest and driest (about $284.5 \mathrm{~K}$ and $\left.8.5 \mathrm{~g} \mathrm{~kg}^{-1}\right)$. The cumulated turbulent kinetic energy (TKE) inside the first $200 \mathrm{~m}$ is plotted in Fig. 9. COBEL-Noah shows large values during the first $5 \mathrm{~h}$ of the simulation (maximum value of $24.26 \mathrm{~m}^{2} \mathrm{~s}^{-2}$ ). This behavior seems to be related to a spinup problem during the first hours of the simulations, which has not been observed for the other NWP models. This spinup problem is intermittent and takes place at various heights. As a consequence, the temperature profiles of COBEL-Noah exhibit a stairlike structure (Fig. 8). For the various models, the cumulated TKE increases gradually with the deepening of the fog layer. The TKE simulated by the COBEL-ISBA model shows fluctua- tions during the growing of the fog layer that are due to a destabilization of the atmosphere at the top of the fog layer: intermittent production of TKE arises when fog appears inside a new vertical grid. This sporadic turbulence increases the vertical mixing inside the fog layer and consequently increases the vertical development of the fog layer.

The simulations initialized at 0000 UTC focus on the mature phase of the fog event. As opposed to the cooling phase, the dispersion among simulations for temperature and specific humidity is almost constant with altitude between 2 and $45 \mathrm{~m}$ (not shown). After the first hour of simulation, the dispersion among the models does not grow significantly for both temperature and humidity. For the +3 -h forecast (i.e., at 0300 UTC), the dispersion is on the order of $1 \mathrm{~K}$ for temperature and $0.6 \mathrm{~g} \mathrm{~kg}^{-1}$ for humidity. The mean value from the various simulations agrees with the observations. The profiles of the cloud water content at 0300 UTC $(+3-h$ forecast time) are plotted in Fig. 10. Three types of profiles can be identified: tBM has a profile that is nearly constant with altitude, HIRLAM-INM has a maximum value at the ground and decreasing with altitude, and the other models (HIRLAM-DMI, COBEL-ISBA, COBEL-Noah, and Méso-NH) show more typical profiles with maximum values near the top of the fog layer and minimum values near the ground. As a consequence, for these four NWP models the fog is denser in the upper layer than near the surface. HIRLAM-INM and Méso-NH have the largest values of cloud water content near the ground. The net radiation flux profiles at 0300 UTC ( +3 -h forecast time) are plotted in Fig. 11. This figure illustrates well the differences between the models. As previously described, three distinct profiles are found. The tBM shows no significant variation of the net radiation flux with altitude. HIRLAM-INM (the lowest-resolution model) shows a linear decrease of the net radiative flux with altitude inside the fog layer. Three models (COBELISBA, COBEL-Noah, and Méso-NH) show an almost zero net radiation flux inside of the fog layer. At the fog top, these three models simulate a significant radiative flux divergence (about $60 \mathrm{~W} \mathrm{~m}^{-2}$ ). Once the fog layer is dense enough, the divergence of longwave radiation cools the upper part of the fog layer and destabilizes it. This mechanism creates a strong thermal inversion at the top of the fog layer (about $-4 \mathrm{~K}$ ). The lowerresolution models participating in this intercomparison cannot accurately simulate these processes.

\section{d. The dissipation phase}

The simulations presented hereinafter are initialized at 0300 UTC to study the dissipation phase of the fog 

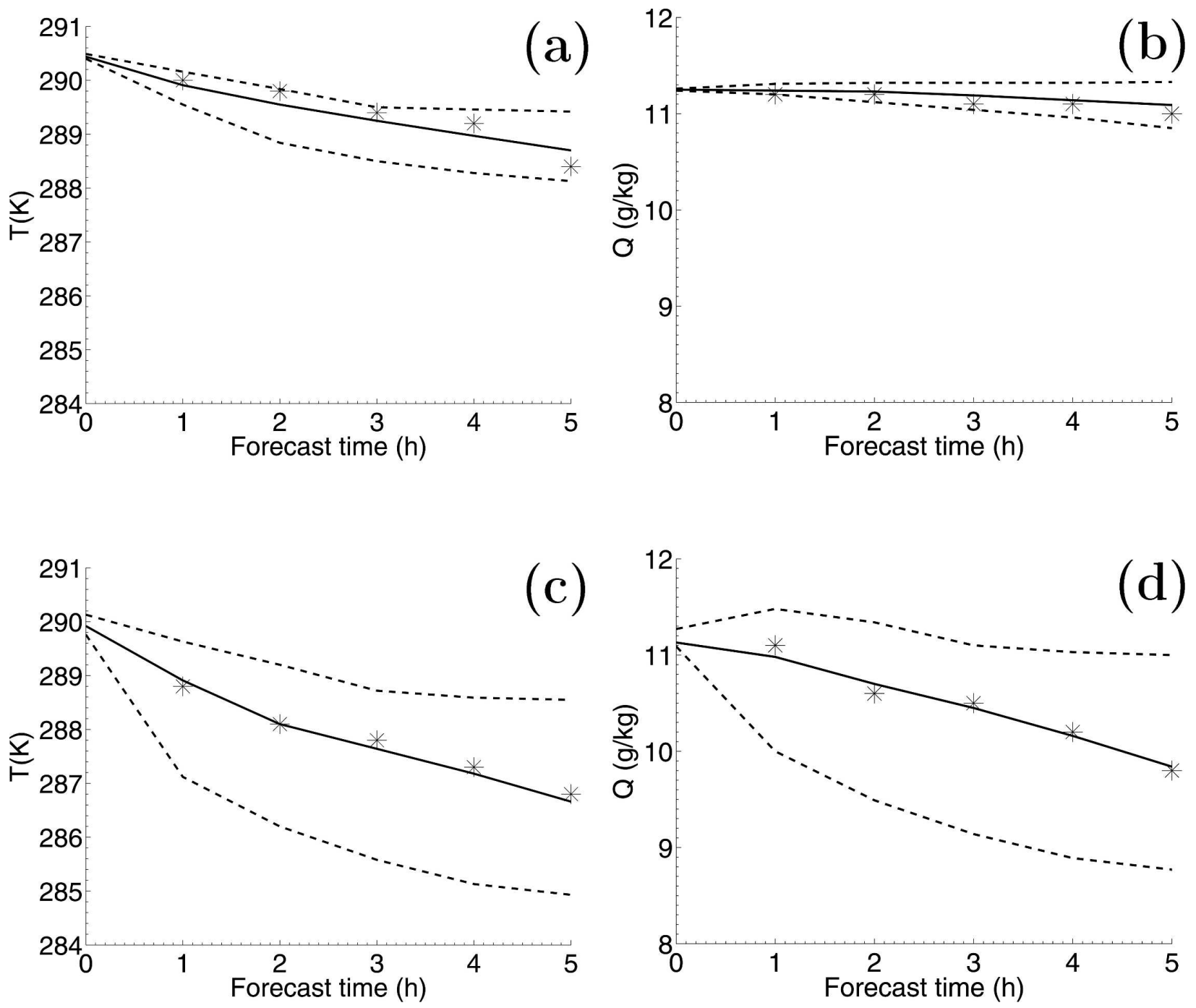

FIG. 6. Dispersion among models for the simulations initialized at 1800 UTC for the FOG case: mean (solid line) minimum and maximum (dashed line) from the forecast temperature at (a) 45 and (c) $2 \mathrm{~m}$ and from the forecast water vapor mixing ratio at (b) 45 and (d) $2 \mathrm{~m}$. The observations are plotted with asterisks.

layer. The occurrence of fog forecast by the various models is plotted in Fig. 3d. The burn-off time of fog at the ground varies from 0730 UTC (COBEL-Noah) to 1130 UTC (Méso-NH). Even for these short-term forecasts starting with the same initial conditions, the dispersion of the dissipation of the fog at the ground is about $4 \mathrm{~h}$. This dispersion is similar to the dispersion for the onset phase. As previously discussed, Méso-NH has an unrealistic value of the cloud water content due to a lack of the representation of gravitational settling in the microphysical parameterization. Therefore, a new simulation called Méso-NH-RR has been performed in which a crude parameterization of the sedimentation has been included (conversion of the sedimentation flux into precipitation). The introduction of this sedi- mentation term leads to a dissipation at 0830 UTC (instead of 1130 UTC without sedimentation). These two simulations (Méso-NH and Méso-NH-RR) demonstrate that the gravitational settling flux cannot be neglected in the fog layer. The liquid water path (LWP) during the dissipation phase is plotted in Fig. 12. A simulation without sedimentation (Méso-NH) leads to very large values of LWP, and they are about 3 times those found for the other simulations. This explains the delay in the burn-off of the fog layer for Méso-NH. The evolution of the simulated LWP shows different characteristics during the dissipation phase. HIRLAM-DMI and tBM show significant increases of LWP between 0600 and 0900 UTC from 20 to $45 \mathrm{~g} \mathrm{~m}^{-2}$, followed by a sudden decrease. The other models (HIRLAM-INM, 


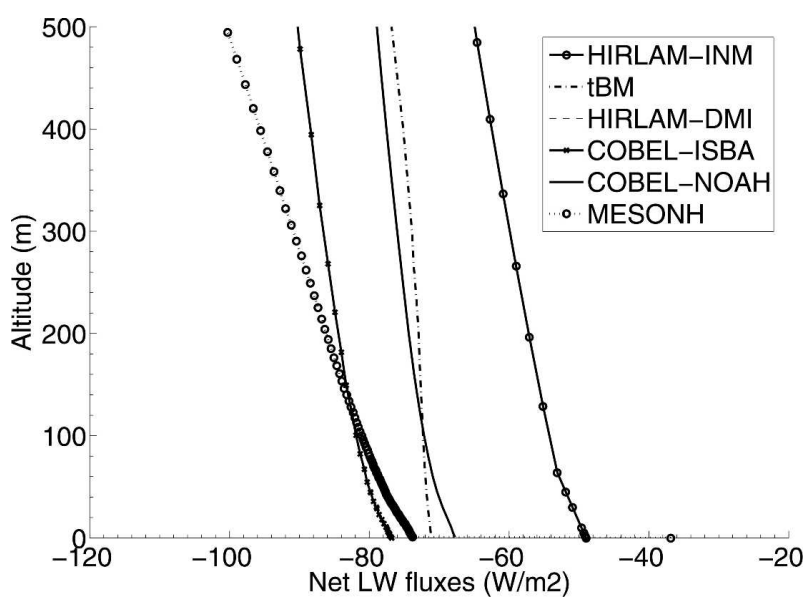

FIG. 7. Profiles of net longwave radiation fluxes at initial time from the simulations initialized at 1800 UTC for the FOG case (radiation fluxes from HIRLAM-DMI are missing).

COBEL-ISBA, COBEL-Noah, and Méso-NH-RR) show a maximum LWP at sunrise followed by a gradual decrease. The temperature profiles at 0600 and 0900 UTC are plotted in Fig. 13. At 0600 UTC, all of the NWP models have forecast a transition toward a mixed layer of fog (as observed), but the lapse rates are somewhat different (e.g., tBM and Méso-NH-RR). Because the solar shortwave radiation increases during this period, the heating rate at the ground becomes higher and an unstable layer appears. This process destabilizes the fog layer and leads to its dissipation. The fog layer starts to dissipate from the surface and transforms into a stratiform cloud. All models follow this scenario for the dissipation of the fog layer, but considerable differences exist in the timing of this process. These differences could be explained by the various LWP, which lead to different heating rates at the ground. One can also notice that simulated temperature profiles from the various models are colder than the observed profile at 0900 UTC. One can suspect mesoscale circulations (organized structures) during the transition period at sunrise. However, the existence of such structures cannot be documented with the observations coming from the Paris-CdG field experiment.

\section{Near-fog event \\ a. Description of the event}

The second case studied in this intercomparison, called "NEAR," corresponds to a case in which the meteorological conditions are very close to being ideal for the formation of fog but in which fog did not form. This event took place during the night between 11 and
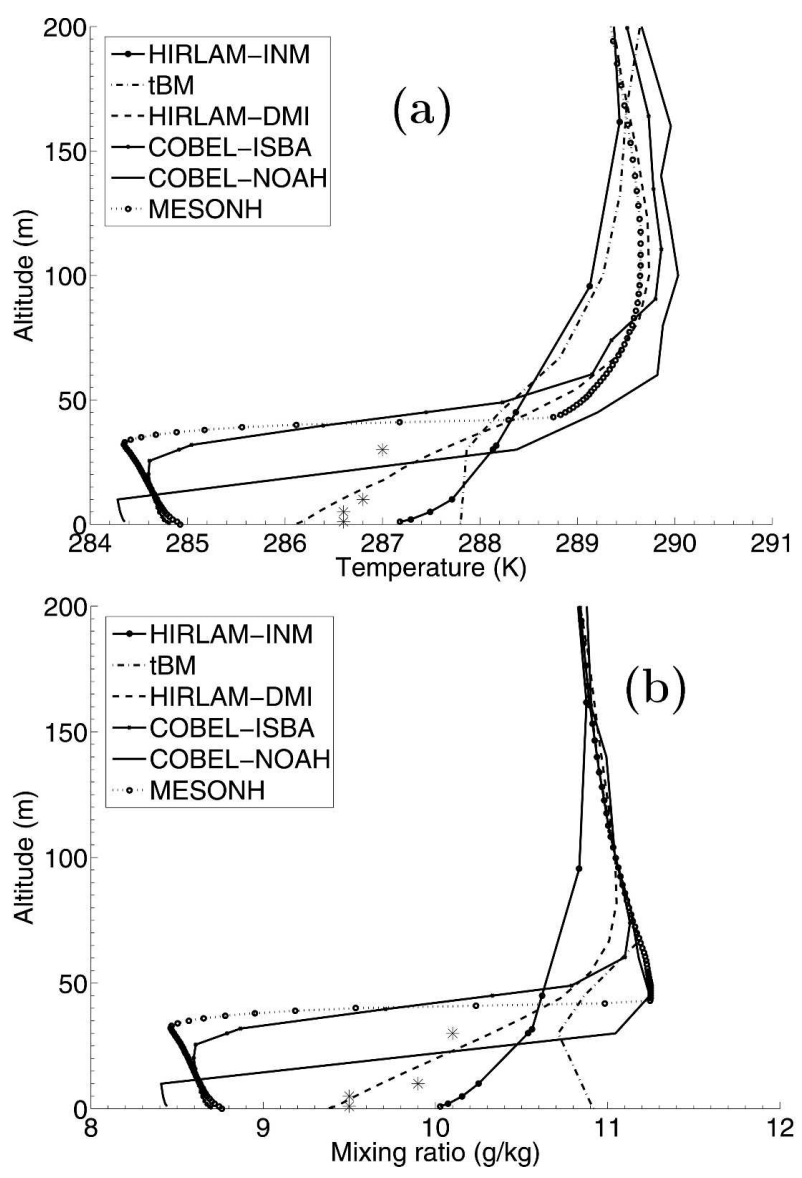

FIG. 8. (a) Temperature and (b) water vapor mixing ratio profiles at 0000 UTC (+3-h forecast) for simulations initialized at 2100 UTC for the FOG case. The observations are plotted with asterisks.

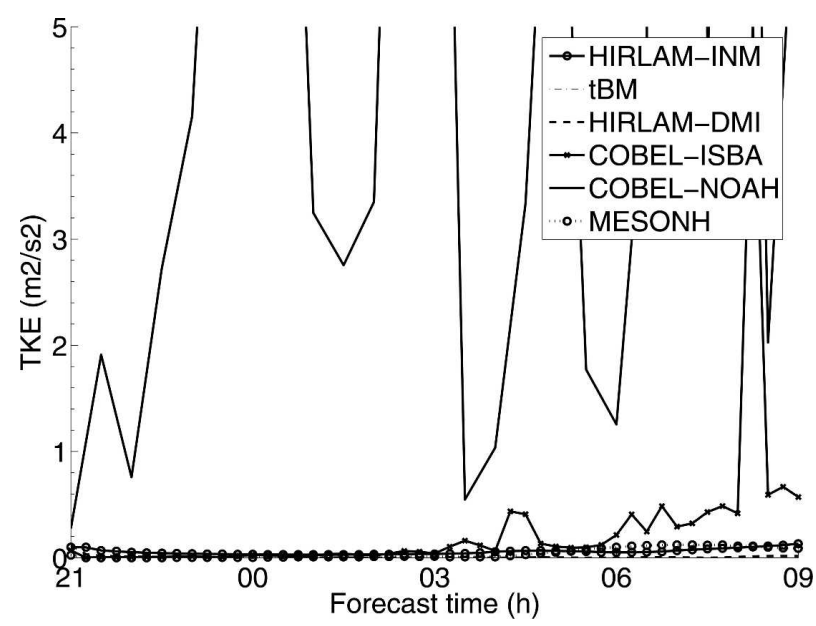

FIG. 9. Temporal evolution of the mean turbulent kinetic energy in the lowest 200-m layer for the simulations initialized at 2100 UTC for the FOG case. 


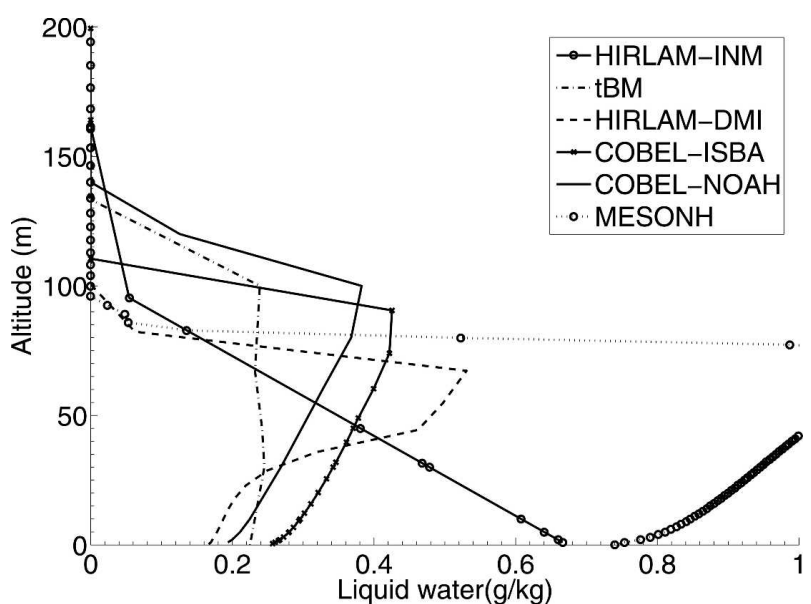

FIG. 10. Profile of liquid water content for +3 -h forecasts for the simulations initialized at 0000 UTC for the FOG case.

12 October 2003. The humidity was around $70 \%$ at sunset and increased during the night to become very close to saturation after 0300 UTC (Fig. 14). The nocturnal cooling near the ground was strong (about $10 \mathrm{~K}$ during the night) and almost linear (Fig. 15). The water vapor mixing ratio near the ground greatly decreased during the night because of dew deposition (Fig. 16). The wind intensity at $10 \mathrm{~m}$ increased at the beginning of the night, from 1 to $3 \mathrm{~m} \mathrm{~s}^{-1}$, and showed significant variability until the middle of the night, with a maximum intensity of about $6 \mathrm{~m} \mathrm{~s}^{-1}$. Afterward, the wind intensity remained moderate (about $3.5 \mathrm{~m} \mathrm{~s}^{-1}$ ) until sunrise (Fig. 17).

This night corresponded to a situation with moderate turbulence and in which a fog layer did not form although the atmosphere near the ground reached satu-

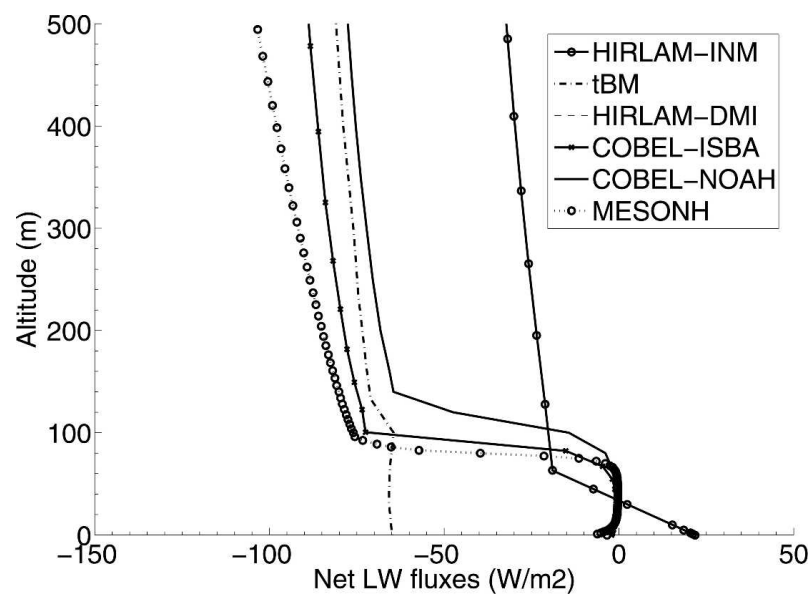

FIG. 11. Profile of net longwave radiative fluxes at 0300 UTC (+3-h forecasts) for the simulations initialized at 0000 UTC for the FOG case. Radiation fluxes from HIRLAM-DMI are missing.
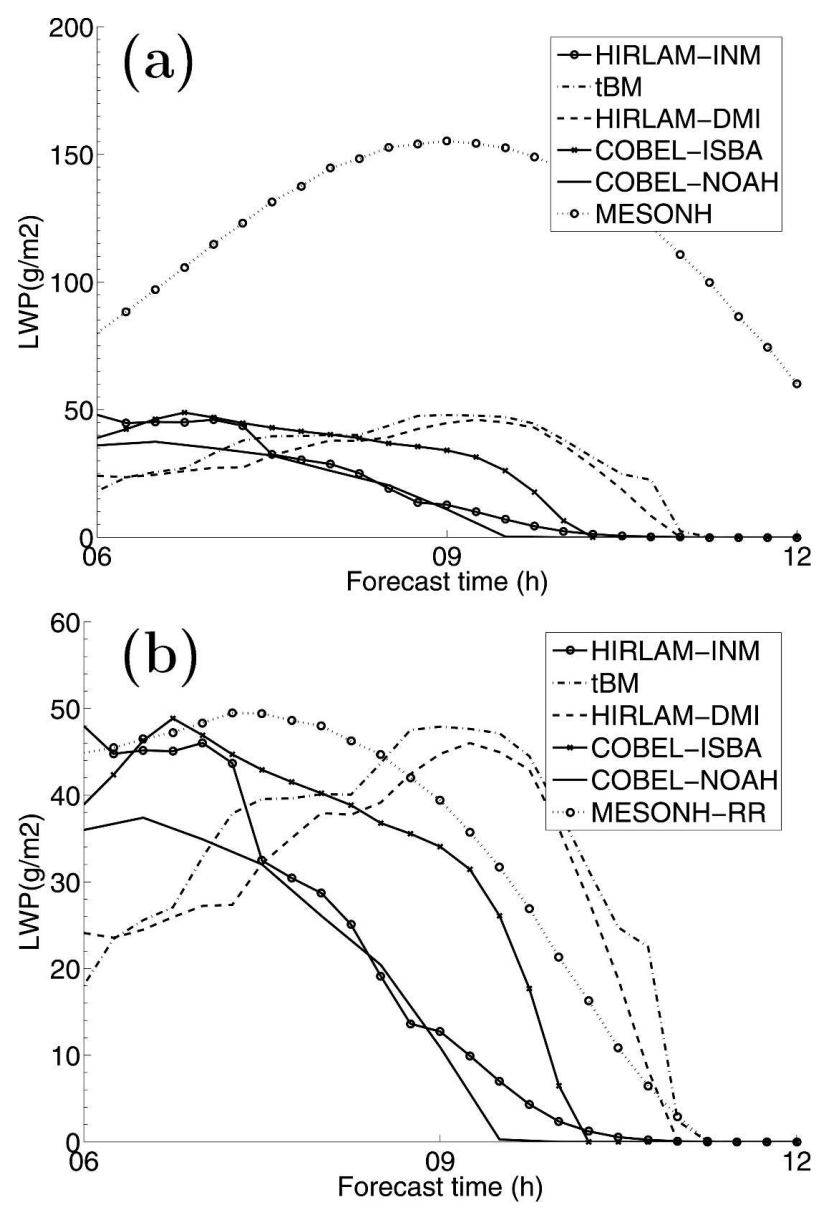

FIG. 12. Temporal evolution of the liquid water path within the fog layer for the FOG case.

ration. This case is typical and illustrates the balance between cooling and moisture loss (dew deposition) in the surface layer during the night. The forecast of this kind of meteorological situation is very sensitive to the physical parameterization (Bergot and Guedalia 1994), and it is helpful to study this kind of event to evaluate the capability of the numerical models to discriminate between fog and near-fog events. To compare the models at different times during the night, four sets of initial conditions have been compiled. The models have been initialized at four different times during the night: 2100, 0000, 0300, and 0600 UTC.

\section{b. Results}

The simulated occurrence of fog during the night for the four sets of initial conditions is plotted in Fig. 18. Except for HIRLAM-INM, all of the models forecast a fog event at least for one simulation. The simulations reveal a weak predictability of fog forecasting for this type of event. This behavior is typical of threshold phe- 

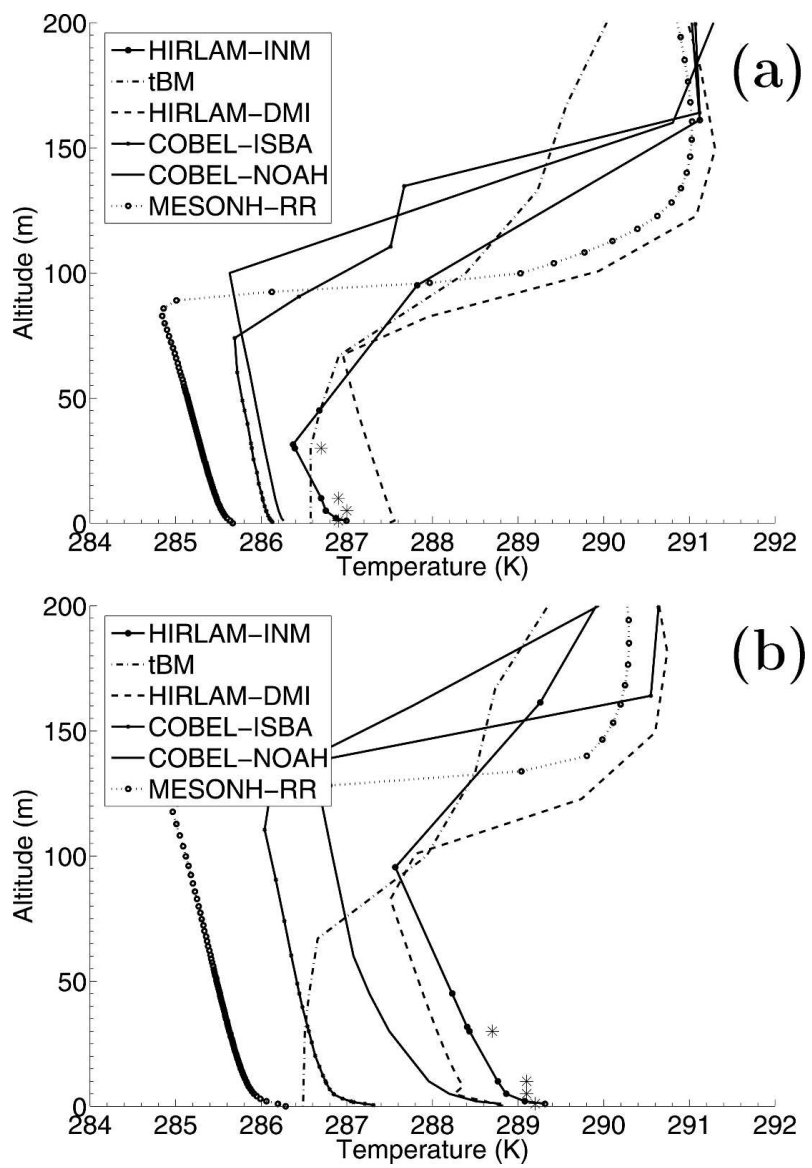

FIG. 13. Temperature profiles at (a) 0600 and (b) 0000 UTC for simulations initialized at 0300 UTC for the FOG case. The observations are plotted with asterisks.

nomena like fog, and therefore these simulations are of interest for pointing out the potential erroneous forecast of fog for this case of event.

Only tBM forecast an occurrence of fog for all initialization times (2100, 0000, 0300, and 0600 UTC). Figure 19 shows the mean total water content (vapor and liquid) within the lowest $200 \mathrm{~m}$ of the boundary layer. In contrast to all other models, tBM does not forecast the decrease of the water content. The difference on the water content at the end of the night between tBM and the other models is important, and it is more than $0.5 \mathrm{~g}$ $\mathrm{kg}^{-1}$ in terms of the mean water content below the nocturnal inversion. The systematic occurrence of fog forecast by tBM seems to be a consequence of a poor parameterization of dew deposition.

For the simulations initialized at 0000 UTC, four models out of six (Méso-NH, COBEL-ISBA, HIRLAMDMI, and $\mathrm{tBM}$ ) forecast an occurrence of fog during the night. If we exclude tBM because of the deficiencies in the dew deposition parameterization that were described previously, the dispersion of the forecast onset

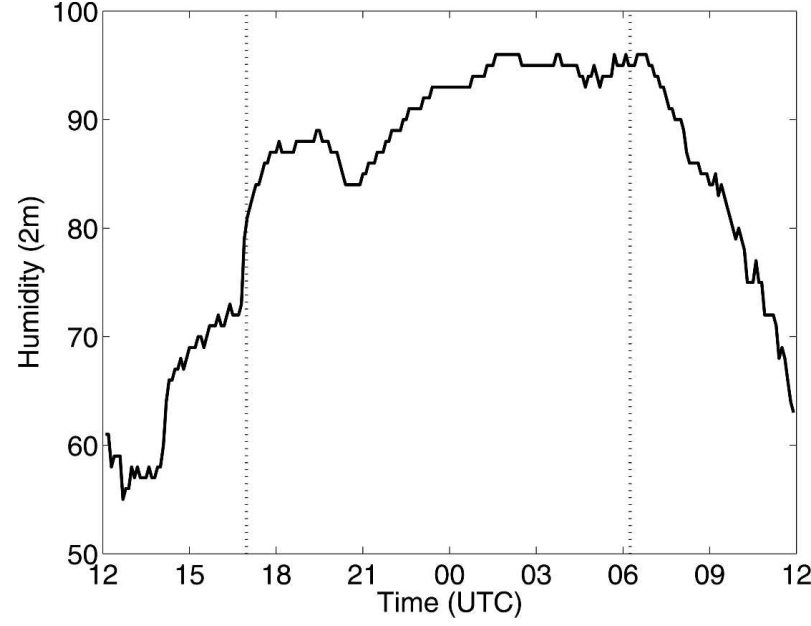

FIG. 14. Temporal evolution of the relative humidity measured at $2 \mathrm{~m}$ for the NEAR case. The dotted line corresponds to the sunset and sunrise.

time is $2.5 \mathrm{~h}$, between 0500 (Méso-NH) and $0730 \mathrm{UTC}$ (HIRLAM-DMI). However, this dispersion is weaker than for the previous event studied, and the forecast onset time is close to sunrise. As previously demonstrated, the gravitational settling also plays a major role for the prediction of the burn-off time. Méso-NH-RR (with sedimentation in the microphysical parameterization) forecasts a fog burn-off at 0800 instead of 1000 UTC for Méso-NH (same model without sedimentation). All NWP models that include the parameterization of gravitational settling and that predict fog agree on the fog burn-off time (0800 UTC $\pm 15 \mathrm{~min})$. The time-height cross section of the cloud water content is

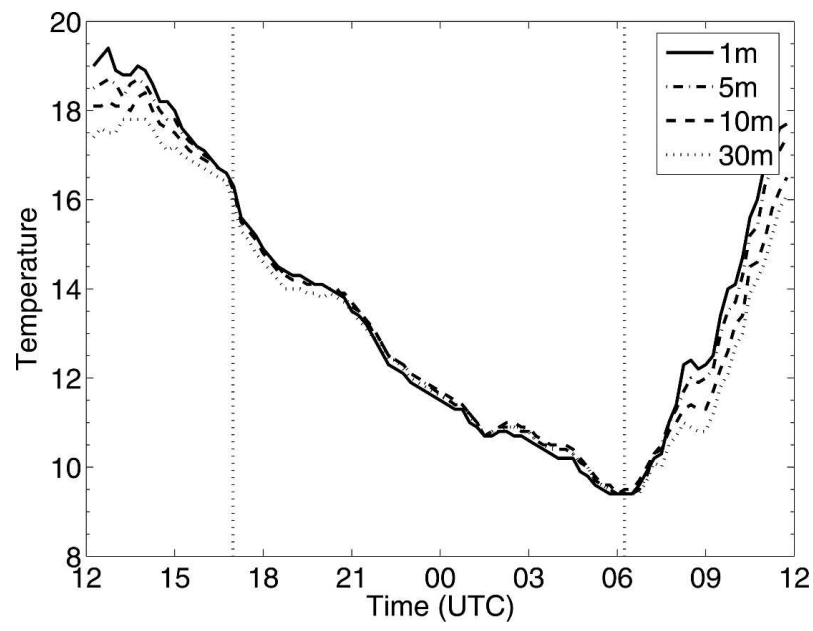

FIG. 15. Temporal evolution of the temperature measured at 1 , 5,10 , and $45 \mathrm{~m}$ for the NEAR case. The dotted line corresponds to the sunset and sunrise. 


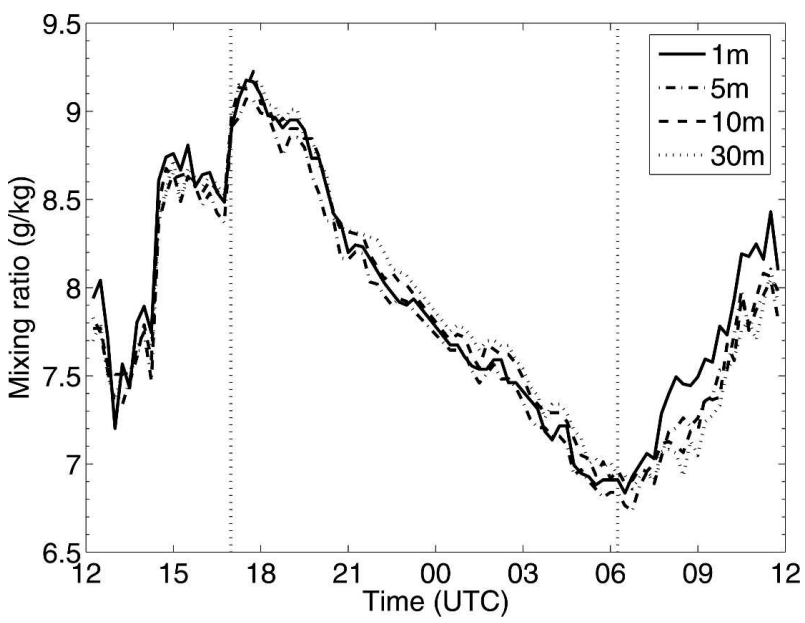

FIG. 16. Temporal evolution of the water vapor mixing ratio measured at 1,5,10, and $45 \mathrm{~m}$ for the NEAR case. The dotted line corresponds to the sunset and sunrise.

plotted in Fig. 20. Despite the good agreement among models on the fog burn-off time, the behavior of the forecast fog layer is very different among the models. The tBM predicts a deep fog layer (100-m height) that disappears suddenly at sunrise. HIRLAM-DMI predicts a very thin fog at the end of the night. COBELISBA and Méso-NH-RR predict a low-level cloud (100-m ceiling) that rapidly reaches the ground. These two models have a similar behavior in that the condensed layer does not appear at the ground but at the top of the nocturnal inversion layer. The simulated fog layer evolves rapidly into a low-level cloud after sunrise, because of the destabilization of the boundary layer. As a consequence, the life cycle of the fog and low clouds differs greatly among the various models that forecast fog.

During the night, the dispersion of the temperature profiles among the various models is weaker than for the previous case studied, and no significant difference has been found with respect to the vertical resolution (not shown). The relative humidity dispersion among models at $2 \mathrm{~m}$ is plotted in Fig. 21. All NWP models forecast conditions very close to saturation near the ground, and the dispersion among the models for relative humidity near the ground is small during the night. The mean forecast value is close to measured values during the night. The dispersion is stronger after sunrise because of the formation of a stratiform cloud by some models. The lowest-resolution model HIRLAMINM is the warmest model for all initialization times. This fact could explain why this model does not forecast fog for any simulation. A significant nocturnal jet of about $8 \mathrm{~m} \mathrm{~s}^{-1}$ at $100 \mathrm{~m}$ has been forecast during the night by all of the models except tBM, HIRLAM-DMI,

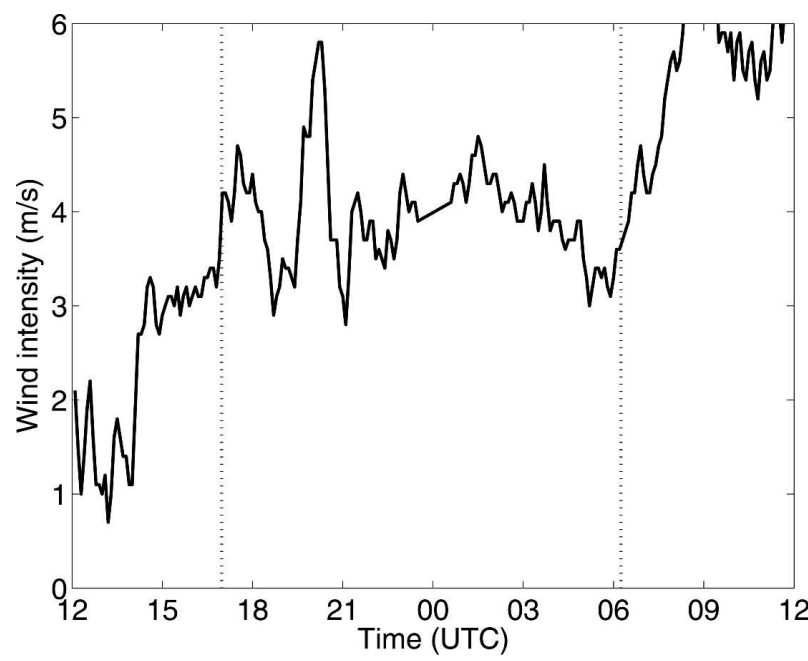

FIG. 17. Temporal evolution of the wind intensity measured at $10 \mathrm{~m}$ for the NEAR case. The dotted line corresponds to the sunset and sunrise.

and HIRLAM-INM (Fig. 22). Because these models include high- and low-resolution grids, no dependence of this low-level jet on the vertical resolution has been found. The formation of this kind of nocturnal jet is typical within the nocturnal boundary layer. It is unfortunate that no observations of the wind profile are available to validate the simulations. The cumulated TKE in the lowest 200-m layer is plotted in Fig. 23. COBEL-Noah has once again the strongest value of TKE during the night $\left(30 \mathrm{~m}^{2} \mathrm{~s}^{-2}\right)$ and shows considerable temporal variation of TKE during the night.

These simulations reveal a high sensitivity of forecast of fog near sunrise despite a relatively good agreement of the relative humidity near the ground. At 0600 UTC, COBEL-Noah forecast a fog layer that forms very rapidly after initialization. During the transition period between the stable and unstable boundary layer at sunrise, the observed water vapor mixing ratio at the ground is close to $7 \mathrm{~g} \mathrm{~kg}^{-1}$ and the simulated one varies from $7.5 \mathrm{~g} \mathrm{~kg}^{-1}$ for COBEL-Noah to $7 \mathrm{~g} \mathrm{~kg}^{-1}$ for Méso$\mathrm{NH}$ and COBEL-ISBA (Fig. 24). However, at the top of the inversion, COBEL-Noah has the driest values, and Méso-NH and COBEL-ISBA have more moist values. The convective boundary layer develops rapidly in COBEL-Noah (200 m for COBEL-Noah at 0700 UTC against $100 \mathrm{~m}$ for COBEL-ISBA). Therefore, it is suggested that the mixing of moister air in a layer just above the surface boundary layer is a key factor in the forecast of a fog layer at sunrise. In near-fog events, the prediction of fog seems to be very sensitive to turbulent processes during the transition period at sunrise, especially for high-resolution NWP models. This high sensitivity could lead to false alarms, as has been demon- 

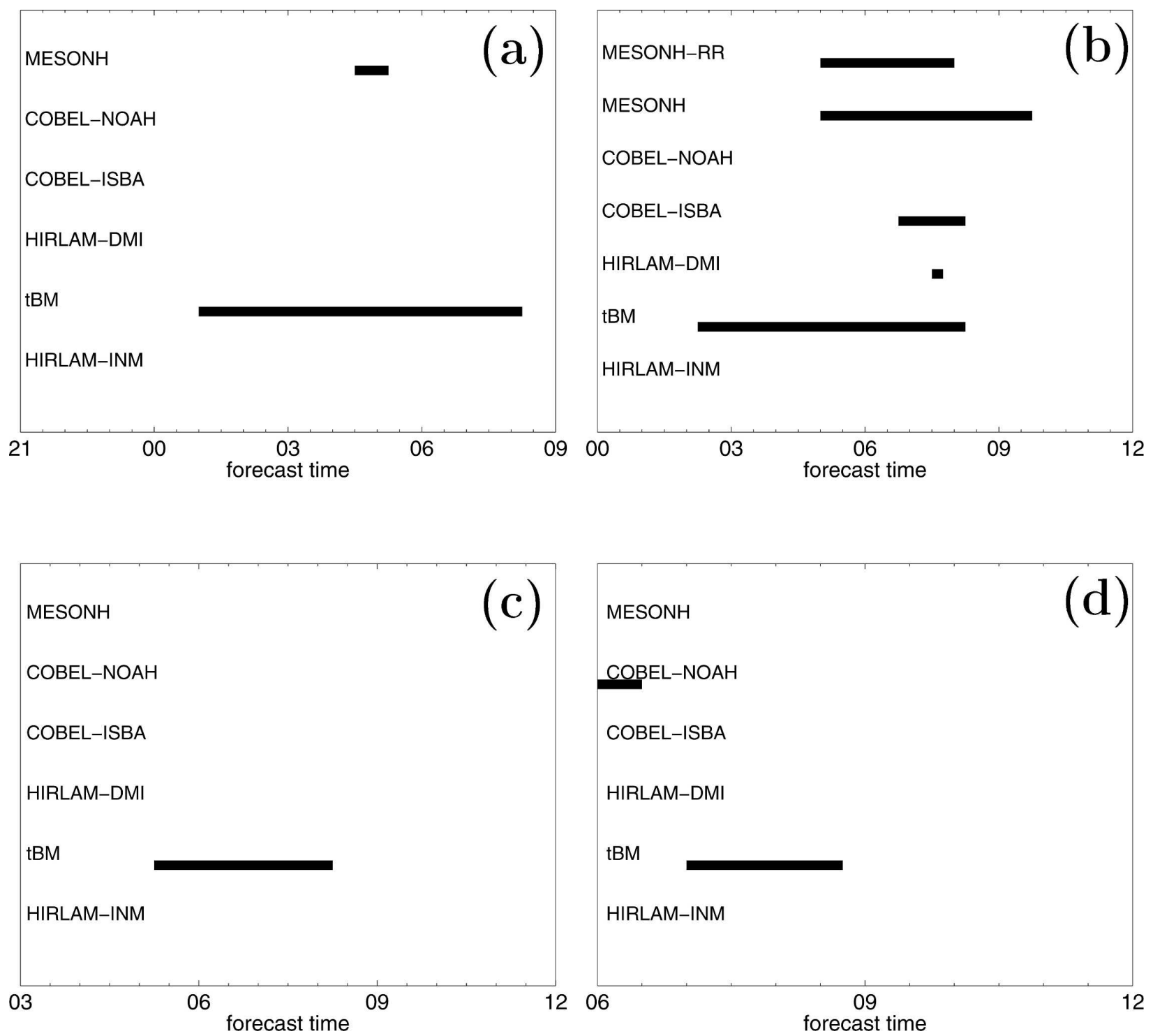

FIG. 18. The forecast occurrence of fog for simulations initialized at (a) 2100, (b) 0000, (c) 0300, and (d) 0600 UTC for the NEAR case. Méso-NH-RR simulation is only done at 0000 UTC.

strated with the simulations of this near-fog event when high-resolution models have forecast at least one fog occurrence. It seems that the predictability of this kind of event is relatively low, even with high-resolution models, because of the extreme sensitivity to the parameterization of turbulent processes.

\section{Conclusions}

Single-column fog NWP model results were analyzed for two events documented during the fog field experiment performed by Météo-France/CNRM at ParisCdG international airport (Bergot et al. 2005). The six different 1D models presented in this intercomparison study included both operational and research numerical models. The two events studied are defined as a classical radiation fog appearing at the beginning of the night and a case in which a fog layer does not form despite the fact that saturation is nearly reached near the ground. For each of these events, four sets of initial conditions have been compiled during the night to study the influence of the initialization time on the forecasts.

First, this intercomparison reveals that significant differences among models appear in terms of the nocturnal cooling near the ground before the onset of fog-in particular, in the case of light wind. With the physical parameterizations used in current numerical weather 


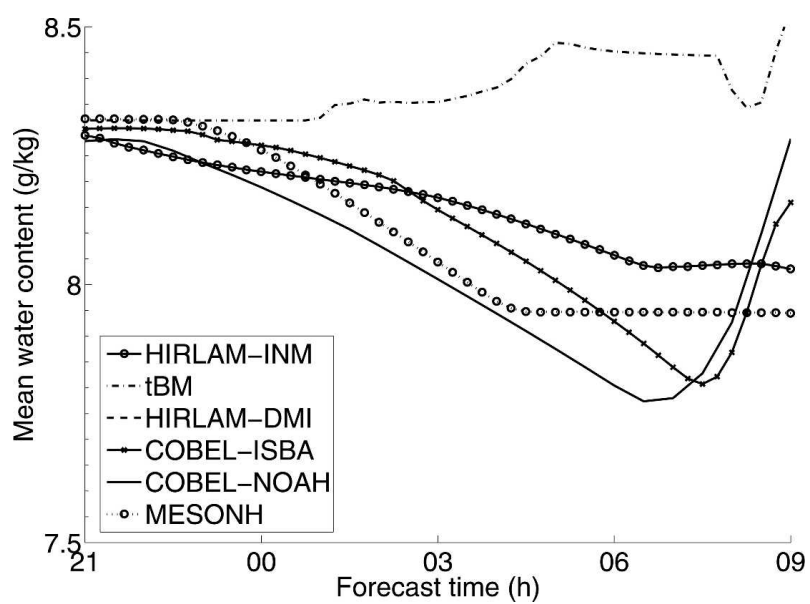

FIG. 19. Temporal evolution of the mean total water content (vapor and liquid) within the lowest $200 \mathrm{~m}$ of the atmosphere for simulations initialized at 2100 UTC for the NEAR case.
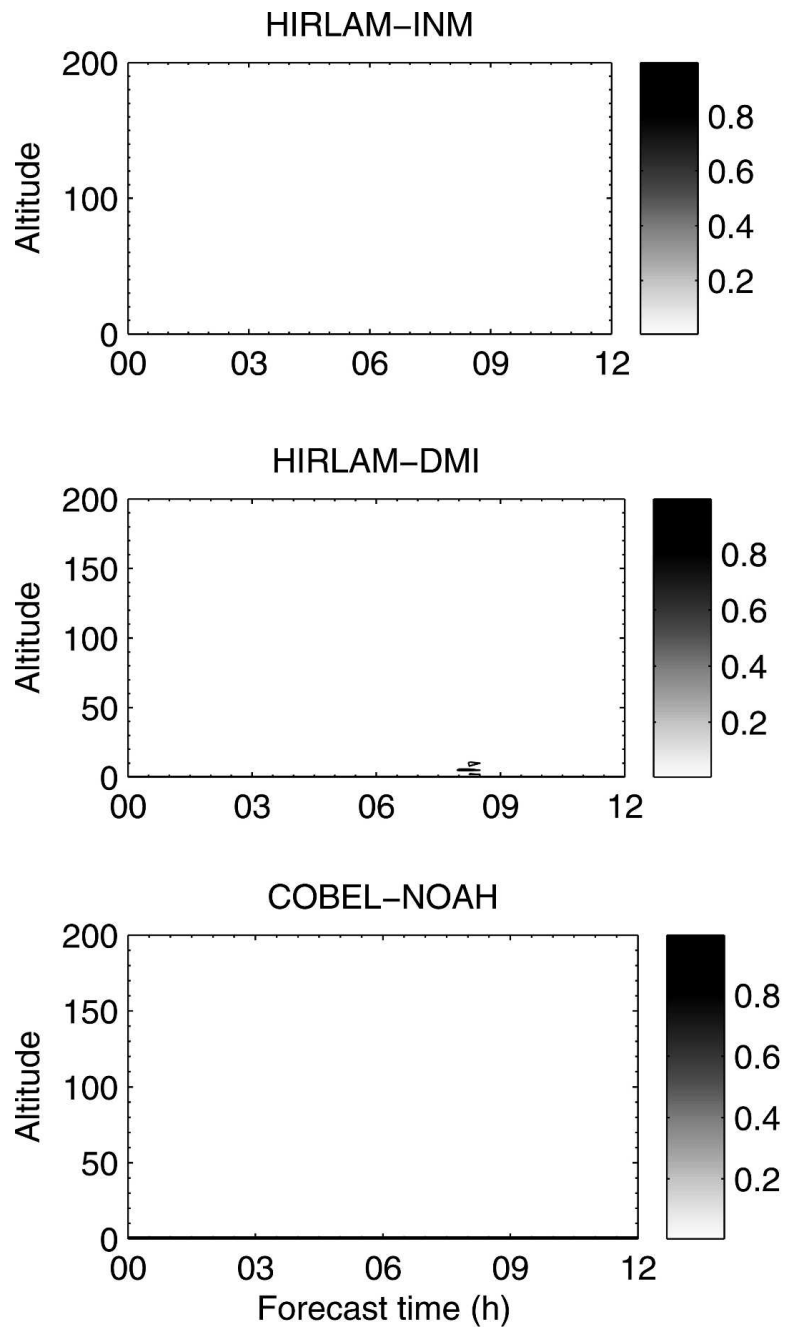

prediction models, an accurate representation of the fine structure of the nocturnal boundary layer and of the strong vertical gradient at the top of the fog layer requires a relatively fine vertical resolution. However, high resolution in itself is not sufficient to simulate correctly the nocturnal cooling and the life cycle of the fog layer. The parameterizations for both the atmospheric and the ground processes must be accurate enough and adapted to fine-mesh models. Refining the resolution of numerical models without improving the parameterization dedicated to both nocturnal boundary layer and fog or low clouds could be the source of numerous problems, like the decoupling between the soil and the atmosphere or spinup problems. As a consequence, high-resolution numerical models do not systematically improve the quality of fog forecasts.

Second, this intercomparison has revealed that single-column numerical models were able to repro-
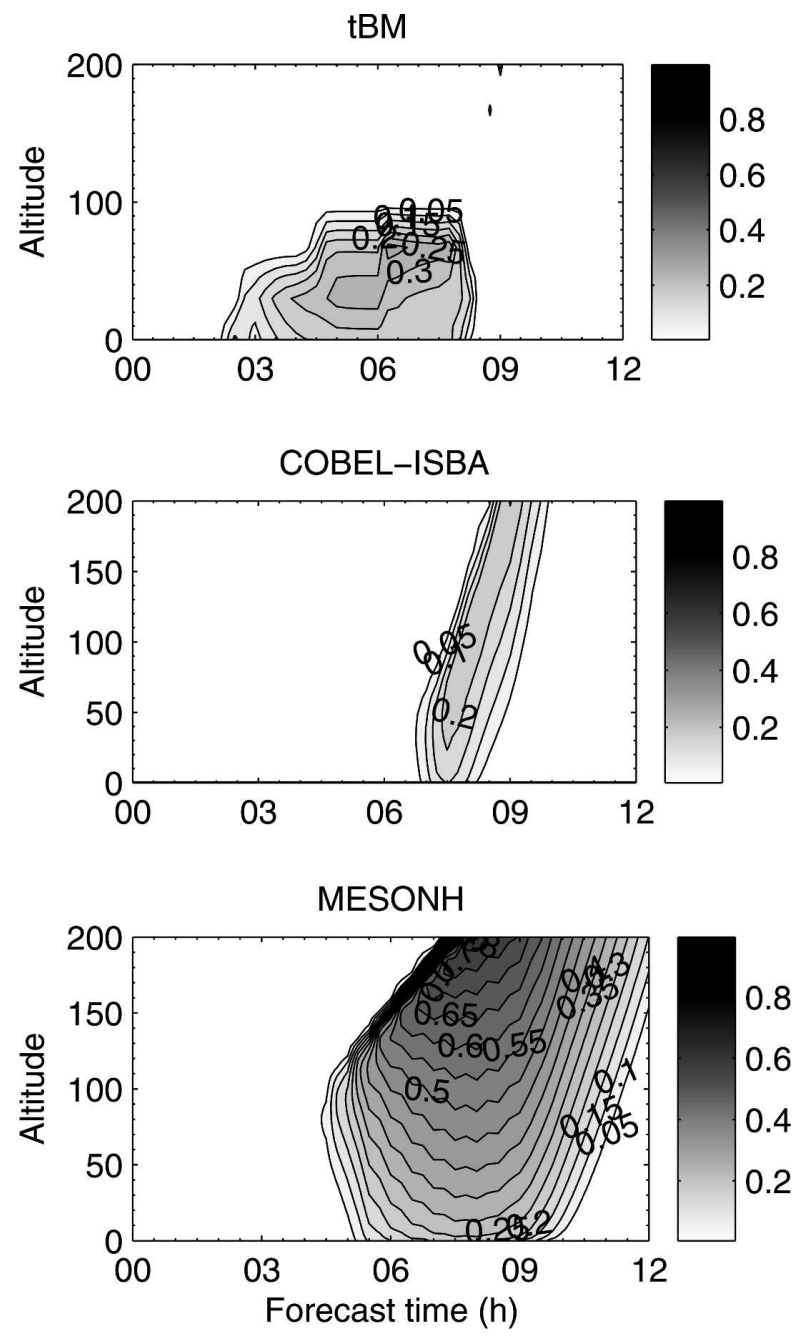

FIG. 20. As in Fig. 4, but for simulations initialized at 0000 UTC for the NEAR case. 

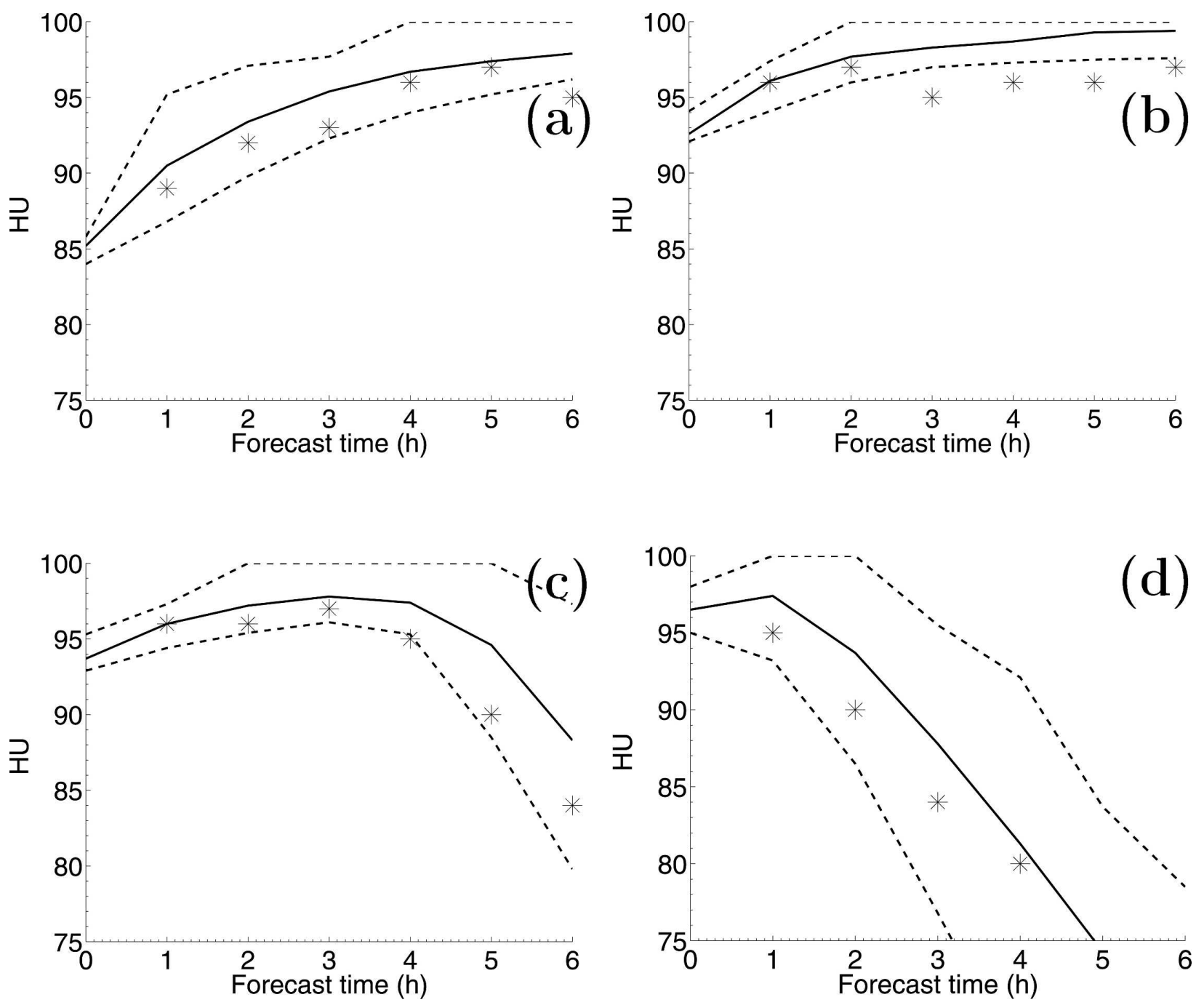

FIG. 21. Dispersion on relative humidity at $2 \mathrm{~m}$ between models for simulations initialized at (a) 2100, (b) 0000, (c) 0300, and (d) 0600 UTC for the NEAR case. The observations are plotted with asterisks.

duce some of the major features of the life cycle of a fog layer studied here, which is characterized by a "dynamical period" characterized by fog growth due to the radiative cooling of the top of the fog layer, which then triggers convection inside the fog layer. However, this intercomparison has demonstrated a high sensitivity to physical parameterizations. The gravitational settling flux cannot be neglected in layers with relatively weak vertical velocity, which is typical of fog events. The absence of the gravitational settling term in the microphysical parameterization leads to unrealistically high cloud water contents inside the fog layer and consequently to significant errors during the fog dissipation phase. Without any sedimentation flux, the predicted fog burn-off is delayed by several hours. However, it has not been possible to discriminate among the different gravitational settling parameterizations (because of

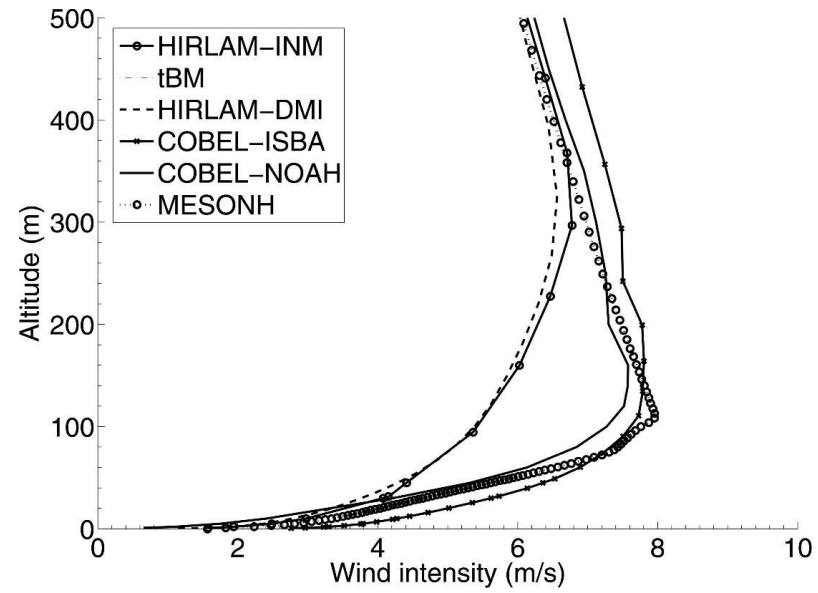

FIG. 22. Wind intensity profiles at 0000 UTC (+3-h forecast) for simulations initialized at 2100 UTC for the NEAR case. 


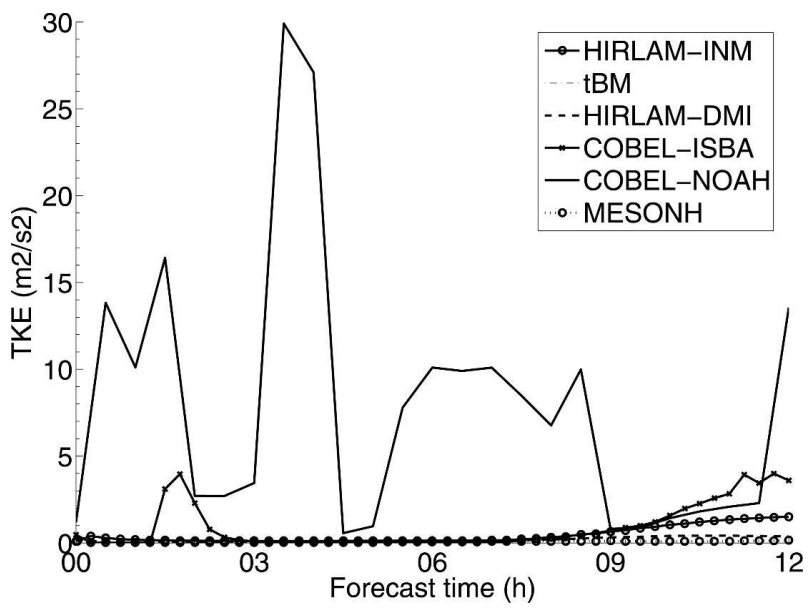

FIG. 23. Temporal evolution of the mean turbulent kinetic energy in the lowest $200-\mathrm{m}$ layer for the simulations initialized at 0000 UTC for the NEAR case.

a lack of detailed microphysical measurements during the Paris-CdG field experiment). The dew deposition also plays a fundamental role in cases in which conditions are close to fog and especially to predict near-fog events accurately. The coarse-resolution numerical models that participated in this intercomparison showed some difficulties in accurately simulating the dew flux at the ground. It was not possible to correct the major deficiencies of the models shown in this intercomparison. It would be helpful in the future to simulate these events again with improved models. However, such work is outside the scope of this article.

This intercomparison has also demonstrated a considerable dispersion between models. Even for very short term forecasts beginning from the same initial conditions, the dispersion among the models in the prediction of the fog onset and burn-off is on the order of several hours. Moreover, in near-fog situations, the uncertainties related to the parameterization of turbulence during the transition period at sunrise or the uncertainties related to dew deposition could possibly affect the forecast.

In the future, this intercomparison project will concentrate on the evaluation of the quality of fog forecasting at several international airports. The goal of this work will be to learn about the quality of the various existing methods for fog forecasting. One goal is to learn more about the predictability of fog events and their dependence on both geophysical and meteorological situations. An increased understanding of the predictability of fog could help to identify ways of taking advantage of the strengths of NWP models and to facilitate the better interpretation and use of numerical guidance related to fog.
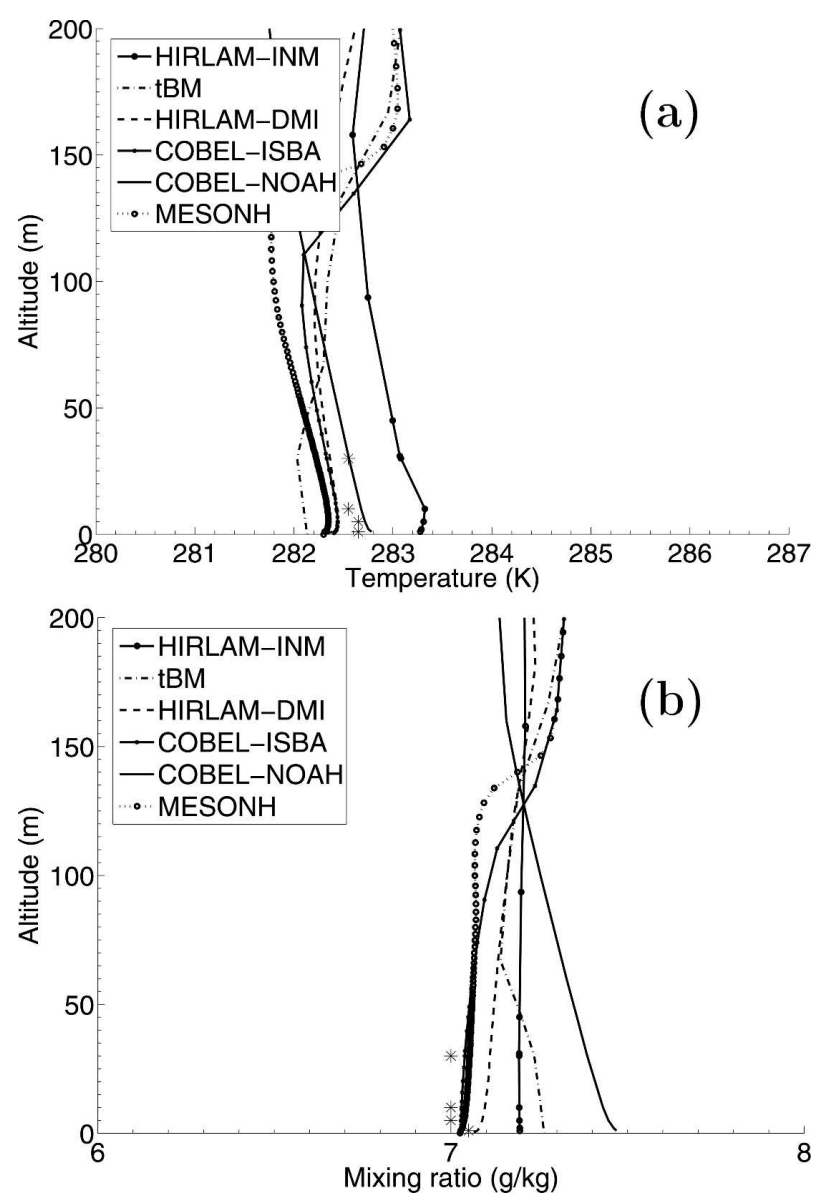

FIG. 24. (a) Temperature and (b) water vapor mixing ratio profiles at 0700 UTC (+1-h forecast) for simulations initialized at 0600 UTC for the NEAR case. The observations are plotted with asterisks.

Acknowledgments. The authors thank R. Tardif, D. Guedalia, and A. Boone for insightful comments on an early version of this article. We also thank the anonymous reviewers for their relevant comments and criticisms. The European Science Foundation ESF/COST is thanked for funding meetings within the framework of the COST722 action.

\section{REFERENCES}

Benjamin, S. G., G. A. Grell, J. M. Brown, and T. G. Smirnova, 2004: Mesoscale weather prediction with the RUC hybrid isentropic-terrain-following coordinate model. Mon. Wea. Rev., 132, 473-494.

Bergot, T., and D. Guedalia, 1994: Numerical forecasting of radiation fog. Part I: Numerical model and sensitivity tests. Mon. Wea. Rev., 122, 1218-1230.

_ D. Carrer, J. Noilhan, and P. Bougeault, 2005: Improved site-specific numerical prediction of fog and low clouds: A feasibility study. Wea. Forecasting, 20, 627-646.

Boone, A. A., 2000: Modélisation des processus hydrologiques 
dans le schéma de surface ISBA: Inclusion d'un reservoir hydrologique, du gel et modélisation de la neige (Modeling of hydrologic processes in the ISBA surface scheme: Inclusion of a hydrologic reservoir, freezing, and modeling of snow). Ph.D. thesis, Université Paul Sabatier, 252 pp.

_ J J. C. Calvet, and J. Noilhan, 1999: The inclusion of a third soil layer in land surface scheme using the force-restore method. J. Appl. Meteor., 38, 1611-1630.

Bougeault, P., and P. Lacarrere, 1989: Parameterization of orography-induced turbulence in a mesoscale model. Mon. Wea. Rev., 117, 1872-1890.

Chen, F., Z. Janjic, and K. Mitchell, 1997: Impact of atmospheric surface-layer parameterization in the new land-surface scheme of the NCEP Mesoscale Eta-Model. Bound.-Layer Meteor., 85, 391-421.

Clark, D. A., 2002: The 2001 demonstration of automated cloud forecast guidance products for San Francisco International Airport. Preprints, 10th Conf. on Aviation, Range, and Aerospace Meteorology, Portland, OR, Amer. Meteor. Soc., CDROM, JP1.26.

Cuxart, J., P. Bougeault, and J. L. Redelsperger, 2000: A turbulence scheme allowing for mesoscale and large-eddy simulations. Quart. J. Roy. Meteor. Soc., 126, 1-30.

Duynkerke, P. G., 1991: Radiation fog: A comparison of model simulation with detailed observations. Mon. Wea. Rev., 119, 324-341.

Ek, M. B., K. E. Mitchell, Y. Lin, E. Rogers, P. Grumnann, V. Koren, G. Gayno, and J. D. Tarpley, 2003: Implementation of NOAH land surface model advances in the National Centers for Environmental Prediction operational Mesoscale Eta Model. J. Geophys. Res., 108, 8851, doi:10.1029/2002JD003296.

Estournel, C., and D. Guedalia, 1987: A new parameterization of eddy diffusivities for nocturnal boundary layer modeling. Bound.-Layer Meteor., 39, 191-203.

Fowler, T. L., M. J. Pocernigh, and J. T. Braid, 2006: Quality assessment of the national ceiling and visibility analysis product. Preprints, 12th Conf. on Aviation, Range, and Aerospace Meteorology, Atlanta, GA, Amer. Meteor. Soc., CD-ROM, $\mathrm{J} 1.4$.

Horst, T. W., and J. C. Doran, 1986: Nocturnal drainage flow on simple slopes. Bound.-Layer Meteor., 3, 263-286.

Lafore, J.-P., and Coauthors, 1998: The Méso-NH atmospheric simulation system. Part I: Adiabatic formulation and control simulations. Ann. Geophys., 16, 90-109.

Lenschow, D. H., X. S. Li, C. J. Lu, and B. B. Stankov, 1988: The stably stratified boundary layer over Great Plains. Part I:
Mean and turbulence structure. Bound.-Layer Meteor., 42, $95-121$

Liechti, O., 2002: REGTHERM convection model with local winds. Technical Soaring, Vol. 26, Soaring Society of America, Inc., 2-5.

— tion model for complex topography. Technical Soaring, Vol. 18, Soaring Society of America, Inc., 73-78.

Mahrt, L., 1985: Vertical structure and turbulence in the very stable boundary layer. J. Atmos. Sci., 42, 2333-2349.

— 1999: Stratified atmospheric boundary layers. Bound.-Layer Meteor., 90, 375-396.

Morcrette, J.-J., 1991: Radiation and cloud radiative properties in the European Centre for Medium Range Weather Forecasts forecasting system. J. Geophys. Res., 96, 9121-9132.

Mueller, M. D., M. Masbou, A. Bott, and Z. Janjic, 2005: Fog prediction with parameterized microphysics. Proc. WWRP Int. Symp. on Nowcasting and Very Short-Range Forecasting, Toulouse, France, World Weather Research Program, CDROM, 6.26.

Musson-Genon, L., 1987: Numerical simulation of a fog event with a one-dimensional boundary layer model. Mon. Wea. Rev., 115, 592-607.

Noilhan, J., and S. Planton, 1989: A simple parameterization of land surface processes for meteorological models. Mon. Wea. Rev., 117, 536-549.

Sass, B. H., 1997: Reduction of numerical noise connected to the parameterization of cloud and condensation processes in the HIRLAM model. HIRLAM Newsletter 29, HIRLAM, 37 45.

_ L. Rontu, and P. Raisanen, 1994: HIRLAM-2 radiation scheme: Documentation and tests. HIRLAM Tech. Rep. 16, $42 \mathrm{pp}$.

- N. W. Nielsen, J. U. Jorgensen, B. Amstrup, M. Kmit, and K. S. Mogensen, 2002: The operational DMI-HIRLAM system. DMI Tech. Rep. 02.05, 60 pp. [Available online at http:// www.dmi.dk.]

Terradellas, E., M. R. Soler, E. Ferreres, and M. Bravo, 2005: Analysis of oscillations in the stable atmospheric boundary layer using wavelet methods. Bound.-Layer Meteor., 114, 489-518.

_ and D. Cano, 2006: Assessment of the fog and low clouds forecasts produced by the H1D single column model. Abstract, Sixth Annual Meeting of EMS, Ljubjana, Slovenia, European Meteorological Society, E.M.S. 2006-A-00220. [Available online at http://www.cosis.net/abstracts/EMS2006/00220/ EMS2006-A-00220.pdf.] 